\title{
NanoStructured Sonogels
}

Nicolás de la Rosa-Fox ${ }^{\mathrm{a})^{*}}$, Víctor Morales-Flórez ${ }^{\mathrm{a})}$, Manuel Piñero ${ }^{\mathrm{b})}$ and Luis Esquivias ${ }^{\mathrm{c}}$.

a) Departamento de Física Materia Condensada. Facultad de Ciencias

${ }^{b)}$ Departamento de Física Aplicada. CASEM.

Universidad de Cádiz. 11510 Puerto Real (Cádiz). SPAIN.

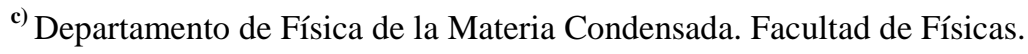

Instituto de Ciencias de los Materiales de Sevilla (CSIC).

Universidad de Sevilla. 41012 Sevilla. SPAIN

Keywords: sol-gel method, sonogel, sonocatalysis, silica aerogel, SAXS, SANS, uniaxial compression, nanoindentation, quantum dots, hierarchical structure, bioactivity, $\mathrm{CO}_{2}$ sequestration.

\section{Sol-gel nanomaterials processing.}

In many fields of the natural sciences the boundary between two subjects is difficult to establish, and the frontier between extended solids and nanostructured materials is no exception. The difference between the macro and nano scales is both quantitative and qualitative. It is well established that a material can be considered "nano" when the grain size scale extends from the molecular level $(0.1 \mathrm{~nm})$ up to around $100 \mathrm{~nm}$; that is, from a physico-chemical point of view, it extends from the scale of the chemical bond, where its behaviour is governed by quantum mechanics, to the mesoscopic systems $(100 \mathrm{~nm})$, at which specific models still are needed, before passing to the macroscopic level.

Nanostructured materials take advantage of properties that derive from confinement effects, larger interface-to-volume ratios, links between wave phenomena and structural features, and where new atomic and macromolecular structures can be generated. The criteria currently used to identify a nanostructured material is the existence of a size-dependent physico-chemical property in such materials, but it is not safe to extrapolate from this up or down in scale. From current work on the development of nanostructured materials the question arises of how the various different properties change as the microstructural scale descends to nanometre dimensions.

One of the most astonishing examples of the size-dependent property is the well-known Hall-Petch equation $[1,2]$ relating the mechanical strength or $\sigma$ value of crystalline materials with the grain

\footnotetext{
*To whom all correspondence should be addressed: nicolas.rosafox@uca.es
} 
size $\mathrm{d}\left(\boldsymbol{\sigma} \propto \boldsymbol{d}^{-\mathbf{1} / \mathbf{2}}\right)$, giving novel properties such as superplastic behaviour. A second example is nanocrystalline semiconductors, such as quantum dots embedded in a dielectric matrix, in which the energy band gap $\mathrm{E}$ is blue-shifted as a function of the crystal radius $\mathrm{R}$ ( $\boldsymbol{E} \propto \boldsymbol{R}^{-\mathbf{2}}$ ) according to the Efros-Efros model [3, 4], and this explains its non-linear optical behaviour. Many other examples can be found in the recent literature but, as the scale is reduced, the yield limits need to be established and new mechanisms need to be explored and studied.

A nanostructured material is thus recognized because it is formed from the assemby of either nanoparticles, nanocrystals or nanolayers, which can be adapted to specific requirements in a dispersion or a coating, functional nanostructures, compacted materials, biological systems, etc. On this point, it is interesting to recall the unusual appearance of the Roman Lycurgus Cup, made of glass and dating from the 4th century B.C.,[5], which looks green in reflected light and red in transmitted light; this effect is due to the gold and silver nanometer particles inside the glass.

Nowadays, manufacturing processes have been designed to take advantage of the following effects:

a) New physical, chemical or biological properties derived from the grain size scaling.

b) New phenomena due to the reduced grain size, where interaction length scales become comparable to the size of the particle, crystal or grain microstructure.

c) The generation of new atomic, molecular and macromolecular structures in materials.

d) The significant increase of the degree of complexity and speed of processes in particulate systems.

All of these characteristics or effects give rise to novel mechanical, optical, electric, magnetic, thermal, chemical and biological properties, but only a small proportion of these properties have been fully identified and quantified [6]. In addition to interesting physical properties in the fields of magnetism, catalysis and optics, materials of this class exhibit a wide range of fascinating mechanical behaviours. Superplastic deformation behaviour has been observed at significantly lower temperatures in nanoscale ceramic powders. Ultra-high hardness values have been measured in nanoscale super-lattices made of metallic and ceramic materials. Tensile and compressive strengths in nearly all material systems studied have shown anomalously high values at the nanometre-length scale [7].

In this chapter we describe one of the modern strategies for building nanomaterials, known as the sol-gel method. This process is widely used for the preparation of multicomponent nanostructured materials by the hydrolysis and polycondensation of metal alkoxides. In 1844 Von 
Ebelmen reported the first synthesis of a metal alkoxide from $\mathrm{SiCl}_{4}$ and alcohol that gelled on exposure to moisture in the air [8]: he wrote "it is permitted to hope that it could be used in the construction of optical instruments". But it was Thomas Graham who prepared silica organosols in 1864, and coined the terms "sol" and "gel" [9]. Much later, in 1918, Walter Patrick of the Silica Gel Corporation was the pioneer in sol-gel derived desiccants, absorbents and catalysts; after firing the silica gel at up to $700^{\circ} \mathrm{C}$, he described the product as "a hard, transparent substance very closely resembling glass in appearance", and obtained many patents that can be studied in [10]. In 1954, Roy and Osborn began to utilize metal-organics as ceramic precursors for many metal oxides [11, 12]. In the early 1960's, the sol-gel approach began to be successfully applied to the preparation of thoria and urania microspheres for the nuclear industry [13], and was also extended to carbides. In Germany H. Dislich [14] prepared a borosilicate glass lens using the sol-gel method, in the early 1970's, and since then the science and associated technology of sol-gel processes have shown marked advances which are continuing to this day.

The primary purpose of this method is to produce very specific composite materials, and among the most important of these are nanomaterials. The main processes involved in this method begin at the molecular level; hence it is possible to act on the structure at the very initial stages. Applications of the method include the tailoring of mechanical, optical, electronic, and chemical properties for sensors, bio-composites, structural and other materials, which are used in all kinds of manufacturing industry [15].

As a process, sol-gel refers to the synthesis of an oxide network via inorganic polymerization starting from molecular precursors in solution. The process is frequently related to the preparation of inorganic oxides by the term known as "sweet chemistry". The sol-gel process offers a new approach to the preparation of glass and ceramic materials with many advantages over conventional methods. Pioneers $[14,16]$ claimed that this technique was particularly suitable for the synthesis of complicated multicomponent glasses because the liquid state favours homogeneous mixing with higher purity at temperatures much lower than those of melting for glass or sintering for ceramic powder.

Thus, Schroeder [17] reported the preparation of vitreous layers of individual and mixed oxides $\left(\mathrm{SiO}_{2}, \mathrm{TiO}_{2}\right.$ and others) by hydrolysis and polycondensation of metal alkoxides. Mackenzie [18] included the hydrolysis of metal alkoxides in his compilation of unconventional routes to glasses. But the "explosion" of interest in the sol-gel process can be dated to the early 1980's with the first International Workshop on Glasses and Glass Ceramics from Gels held in Padua (Italy) in 1981 organized by Professor V. Gottardi. This cycle of conferences was promoted by a group of eminent glass scientists including S. Sakka and M. Yamane in Japan, V. Gottardi in Italy, J. Zarzycki in France, H. Schmidt and H. Scholze in Germany, P.F. James in the UK and J.D. 
Mackenzie in the USA. The proceedings of theses conferences have been published in the Journal of Non-Crystalline Solids and in the Journal of Sol-Gel Science and Technology [19].The highly respected scientists J. Brinker and G. Scherer [20] have written an excellent treatise on 'Sol-Gel Science: The Physics and Chemistry of Sol-Gel Processing' in which the fundamental principles of the sol-gel process and basic applications are comprehensively described.

From a structural point of view a gel can be considered, in the simplest picture, as a giant molecule which has been formed as a consequence of growth by condensation of polymers or aggregation of particles, but no latent heat is evolved. This giant molecule extends to the walls of the vessel that contains it, and the coherent solid 3-D network inside the fluid phase is known as a gel. The solid-phase particles range in size from 1 to $100 \mathrm{~nm}$ [21]. Gels are often classified as particulate or polymeric [22,23]. Particulate means that the solid phase forms by the aggregation of dense, non-polymeric particles. Particulate gels are obtained by the destabilization of an aqueous colloidal solution of oxides, hydroxides, or mineral salts, also known as a colloidal gel. It is also possible to obtain a colloidal gel by hydrolysis and polycondensation of alkoxides in basic catalysis conditions $[24,25]$, in spite of the increase of the silica solubility in these conditions, and the electrostatic interaction plays an important role.

The term polymeric refers to an entangled network of quasilinear chains resulting from the hydrolysis and polycondensation of metal alkoxides. In all cases, the structure of this continuous solid network depends to a large extent on the replacement of the corresponding fluid phase. The term alcogel is used when the pore liquor is alcohol, and hydrogel when it is water. At this stage, the processes of structural change of the gel immersed in the liquid modify the reaction rates, and consequently modify the microstructure. When the pore liquid is removed, we obtain a xerogel if the pore liquid evaporates-slowly at atmospheric pressure and at room temperature, or an aerogel if the pore liquid is vented off in its supercritical conditions of pressure and temperature.

In 1931 the pioneering researcher S.S. Kistler [26, 27] found that gels dried in supercritical conditions did not shrink and showed extremely low densities. Silica aerogels were first prepared systematically from alkoxides by Teichner et al. [28], and developed by Zarzycki et al. [29] to obtain monolithic aerogels with very low density $\left(<0.05 \mathrm{~g} \mathrm{~cm}^{-3}\right)$ and high specific surface areas $\left(>1000 \mathrm{~m}^{2} \mathrm{~g}^{-1}\right)$. In fact, aerogels show unique and unusual properties, such as very low thermal conductivity, a refractive index near that of air, a lower sound velocity and lower dielectric constant than any other solid. These solids have fascinating properties including thermal insulation, Cherenkov radiation detection, fractal geometry, viscoelasticity, optical transparency and catalysis, and several others. Since 1985 the proceedings of the International Symposia on Aerogels (ISA) have been published in the Journal of Non-Crystalline Solids [30]. 
The new era in sol-gel processing was opened by three applications presented at the conference on sol-gel optics in 1994. The first example was presented by D. Levy et al. from Spain [31] concerning liquid crystal display. Liquid crystals dispersed in a silica gel matrix are aligned by an electric field to yield a transparent display but, in its absence, the resulting display is opaque. The second was an optical fibre sensor developed by B.D. MacCraith from Ireland [32]; the cladding at the end of the fibre is removed and substituted by a sol-gel coating with organic dyes embedded in a porous matrix. The third corresponded to a biological parasite detector developed by J. Livage et al. from France [33]; promastigote cells were trapped in a gel matrix, and antigen-antibody interaction results in a colour change. Other promising technological applications of the sol-gel process are coatings and films, organic-inorganic hybrid materials and biological composites.

The new features in coatings and films include ferroelectric, magnetic and photochromic properties, electrical conductors and materials with large third-order optical nonlinear coefficients $[34,35]$. Another active field is the use of organic-inorganic hybrid materials (OIHM) developed from the pioneering work of $\mathrm{H}$. Schmidt in 1985 [36]. He called some of these materials ORMOSILs (ORganic MOdified SILicate) and others ORMOCERs (ORganic MOdified CERamic). The mechanical properties are dependent on the organic content and rubber-like elasticity can replace brittleness [37]. Advantage is taken of the inorganic component that governs the degree of hardness, brittleness and transparency whereas the density, porosity and thermal stability are governed by the organic polymer. Using the classification given by Mackenzie [38], we are now in the second generation of gels including new aerogels with improved mechanical properties, termed "aerormosils" [39]. These include hard coatings for plastic ophthalmic lenses in which the transparency is maintained by the small size of the colloidal particles, and the Ormosil coating reduces the permeation by water, oxygen and numerous other molecules [40]. Considerable progress has been made in the field of nano-building blocks by the co-polymerization of different oxide species [41, 42]. 


\section{Ultrasonically-induced nanomaterials.}

Some of the most important recent developments in sonochemistry have been its application in the synthesis and modification of both organic and inorganic materials. High-power ultrasound can induce a wide range of chemical and physical consequences. The chemical effects of ultrasound can be grouped in three main areas: homogeneous sonochemistry of liquids, heterogeneous sonochemistry of liquid-liquid or liquid-solid systems, and sonocatalysis (which overlaps the other two areas). Applications of ultrasound to materials chemistry are found in all of these categories [43]. Physical effects of high-intensity ultrasound, which often have chemical consequences, include enhanced mass transport, emulsification, bulk thermal heating, and a variety of effects on solids.

In all of these cases the process is conducted by means of acoustic cavitation effects. When the sound wave propagates in a medium it travels via a series of compression and rarefaction stages induced in the molecules through which it passes. At sufficiently high intensity the rarefaction cycle may exceed the attractive forces of the molecules and cavitation bubbles will form. Such generated bubbles grow by a process known as rectified diffusion i.e. small amounts of vapour (or gas) from the medium enter the bubble during its expansion stage but this vapour is not fully expelled during the compression step. The bubbles continue to grow over a few cycles until reaching an equilibrium size for the ultrasound frequency applied. It is the fate of these bubbles to collapse in succeeding compression cycles, at which point they act as a "hot spot" [44], as shown in Fig. 1.

Fig. 1. Ultrasonic cavitation can produce bubbles in liquids. Along this process the bubbles oscillate induced by the pressure cycle of the sound wave. Eventually they undergo a violent collapse, which generates hot-spots of extremely high pressures (1000 Atm) and temperatures (5000K), in lifetimes of less than $2 \mu \mathrm{s}$.

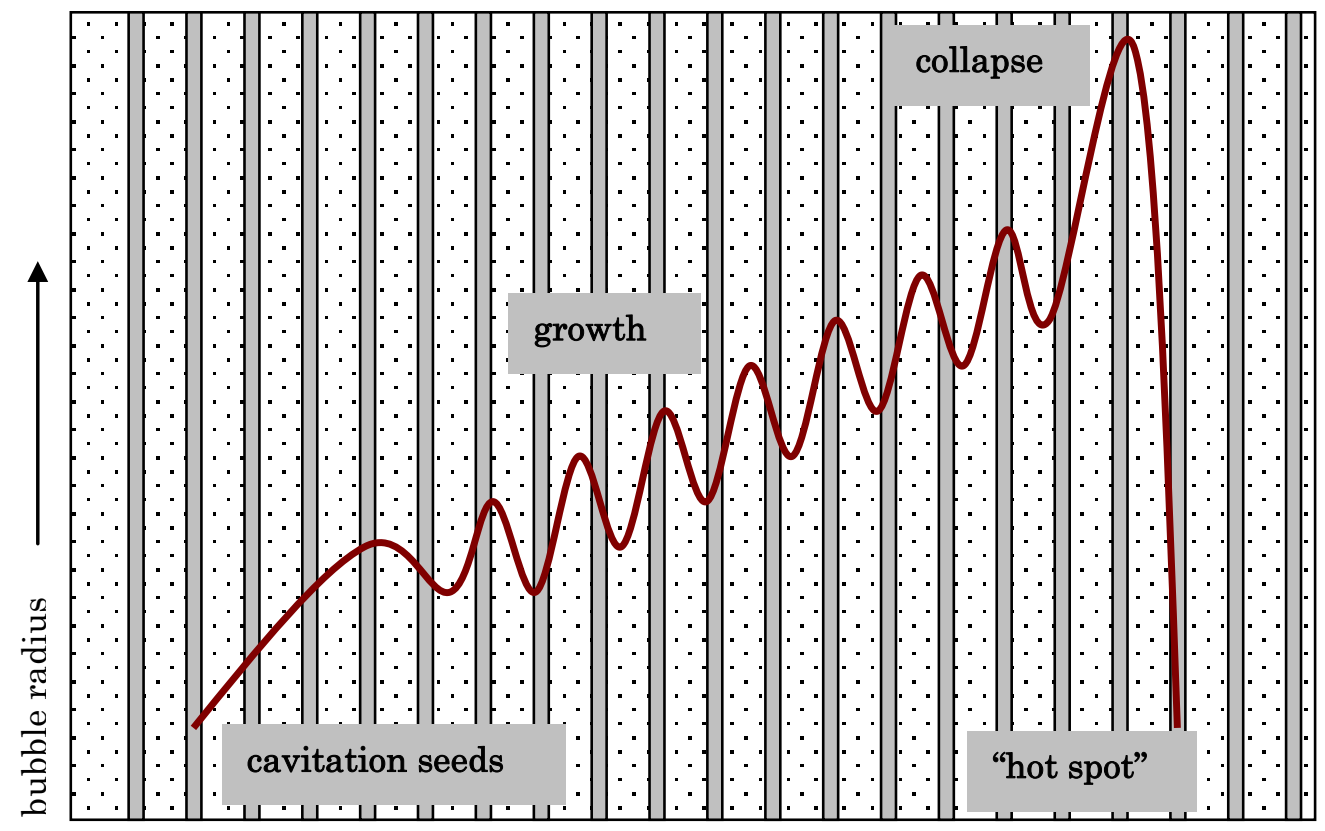


Thus the chemical consequences of the use of high-power ultrasound do not arise from an interaction of acoustic waves and matter at a molecular or atomic level. Instead, in liquids submitted to high-power ultrasound, acoustic cavitation (a process which takes place in three steps: the formation, growth and collapse of bubbles) provides the primary mechanism for sonochemical effects $[45,46]$. During cavitation, bubble collapse produces intense local heating, high pressures, and very short lifetimes; these transient, short-lived localized hot spots provide enough high-energy to generate the chemical reactions. As described in detail by Suslick et al. [47], these hot spots can reach temperatures as high as $5000 \mathrm{~K}$, pressures of about $1000 \mathrm{~atm}$, and heating and cooling rates above $10^{10} \mathrm{~K} / \mathrm{s}$, all in a time scale of the order of picoseconds [48].

Thus, cavitation hot spots can be used as chemical nanoreactors because they serve as a means of concentrating the diffuse energy of sound into a unique set of conditions to produce unusual materials from dissolved (and generally volatile) precursors. Liquid motion in the vicinity of the bubble also generates very large shear and strain gradients; these are caused by the very rapid streaming of solvent molecules around the cavitation bubble, as well as the intense shockwaves emanated on collapse. These physical effects are primarily responsible for such enhancements including:

a) Improvement of mass transport from turbulent mixing and acoustic streaming.

b) Generation of surface damage at liquid-solid interfaces by shock waves and micro jets.

c) Generation of high-velocity interparticle collisions in slurries.

d) Fragmentation of friable solids to increase surface area.

When the cavitation process takes place near solid interfaces the effect is different from cavitation in pure liquids. The bubble becomes non-spherical, driving high speed jets of liquid onto the solid surface, and creates shockwave damage directed onto the surface. This process can also accelerate solid particles, which collide and can induce striking changes in surface morphology, composition and reactivity [49]. As Doktycz and Suslick point out, fine ceramic or metallic powder particles are too small to perturb the ultrasonic field; at $20 \mathrm{kHz}$ the collapsing bubble will have diameter of $150 \mu \mathrm{m}$ and particles smaller than this cannot cause microjet formation. However, the shock wave can cause small particles to collide with great force, producing interparticle binding by localized melting at the site of impact. They report such phenomenon for $\mathrm{Zn}$ powder, as can be seen in Fig. 2, where the particles have an average diameter of $5 \mu \mathrm{m}$, and they suggest that the "neck" is originated from the rapid cooling when the colliding particles rebound after the impact. 
In addition to the above physico-chemical effects of ultrasound by means of cavitation, among which are the promotion of sonochemical reactions, erosion of hard materials and even the rupture of cells, acoustic cavitation in liquids can produce emission of light known as sonoluminescence, as shown in Fig. 3. This interesting phenomenon was first observed in water by Frenzel and Schultes [50]. Because the energy of the visible photons emitted can exceed the energy density of the sound by about twelve orders of magnitude, this effect can explain the temperatures of thousands of degrees Kelvin produced during the bubble collapse [51]. Moreover, as cavitation is a nucleation process, the liquid contains a large number of interacting bubbles that can produce the so-called multiple-bubble sonoluminescence, which is produced from the compressional heating of the contents of the bubbles during collapse. In this case the simplest model for cavitation assumes adiabatic compression during bubble collapse, and uses the equation of Poisson as a function of the initial and final spherical radii of the bubble. The equation provides only an approximate model, but the authors [52] found temperatures in the range of 3000 to $5000 \mathrm{~K}$, depending on both the polytropic ratio and the thermal conductivity of the gas contained in the bubble (inset in Fig.3).

Given certain critical properties of the ultrasound, the cavitation bubble can function as a chemical nanoreactor. In these conditions, the decomposition of volatile organometallic precursors in low-volatility solvents, in each cavitation bubble, is one of the best ways to produce nanostructured materials in various forms; metals, alloys, oxides, carbides, sulphides and nanometre colloids can all be prepared by this route [43]. The applications can be divided in two main categories, one of which is to synthesise nanostructured inorganic materials and the other is to obtain hybrid inorganic-polymer materials, including biomaterials.

An example of the former is the production of amorphous Fe and Co, the formation of which is the consequence of the high cooling rate during acoustic cavitation. The scanning micrograph (Fig. 4) shows an agglomerate of $20 \mathrm{~nm}$ size particles, each one consisting of smaller sub-particles of 4-6 $\mathrm{nm}$, forming a hierarchical two-level structure. Semiconductor nanocrystals embedded in a dielectric matrix is another example of such materials; in this case, sulphide nanocrystals of CdS, $\mathrm{CdSe}$, and $\mathrm{PbS}$ are precipitated inside the silica sonogel. By using a surface capping agent (SCA) it is possible to control the crystal growth, giving crystal sizes that show quantum size effects when excited by high intensity laser beam [53]. In the case of $\mathrm{MoS}_{2}$ which is used as a lubricant, its good layered crystal structure is obtained by high-power ultrasound, and this seems to improve its lubricant property [43], as illustrated in Fig. 5.

In the case of polymers, the physico-chemical effects of ultrasound on these materials range from the acceleration of polymerization to monomodal molecular weight distribution and polymer chain degradation. These effects can be tailored to obtain novel nanomaterials. As an initial 
classification, Price [54] described the conditions for polymer synthesis from the classification proposed by J.L. Luche [55] for sonochemical reactions, known as "Luche's rules":

- Type 1: Produced in homogeneous solution, where single electron transfer processes will occur to give radical intermediates. Then ligand cleavage reactions will give coordinatively unsaturated species. In this case, purely ionic species should not be sensitive to sonolysis.

- Type 2: Produced in heterogeneous systems; in this case ionic reactions can be stimulated by mechanical shock waves provoked by cavitation effects. In this type the products will be the same as in the absence of ultrasound.

- Type 3: Produced in heterogeneous systems which can follow an ionic or radical mechanism, sonication will favour the latter.

Degradation (meaning an irreversible lowering of the chain length caused by cleavage, and not necessarily any chemical change) proceeds more rapidly at higher molecular weights and approaches a limiting value, below which no further degradation takes place. These effects have been reported in many types of macromolecules in solution, and include both organic [56] and inorganic (e.g. poly(organosiloxanes) and polyorganosilanes [57]) polymers in organic solvents, and various polymers in aqueous solution, such as PEO, cellulose, polypeptides, proteins and DNA. Thus, degradation can be used as an additional processing parameter to control the molecularweight distribution. A second application of degradation uses these macromolecular radicals as initiating species in the preparation of copolymers, leading to formation of a block copolymer. In many cases these mixed systems improve the physico-chemical properties of the materials by crosslinking formation in the middle of the linear chains.

In an opposite way, ultrasounds can be used to promote the polymerization by the ring-opening process of cyclic monomers, like cyclic siloxans, followed by polymerization to high molecular weight, also enhancing the cross-linking formation. This process is described by Nikitenko et al. [58] for the polymerization of diphenylmethane (DPhM) by sonolysis, using ultrasound at $20 \mathrm{kHz}$, $0.5 \mathrm{~W} / \mathrm{ml}$ acoustic power, $1 \mathrm{~cm}^{2}$ horn tip surface area and a sonicated volume of $100 \mathrm{ml}$ under argon at $60^{\circ} \mathrm{C}$. They prove that sonolysis of $\mathrm{DPhM}$ causes the breakup of the aromatic ring, as the principal effect of ultrasound. For organic-polymer systems, the use of $\alpha$-olefins and vinyl monomers with reactive double bond, which undergo chain growth, is also reported. In the case of vinyl monomers, ultrasound provides a highly controllable method for polymer initiation. The method has been applied to polyesters, polyurethanes and nylons, taking the advantages of the ringopening mechanism provided by a cyclic monomer.

In the case of biomaterials, the use of ultrasound has been demonstrated to be effective for the formation of protein microspheres, illustrated in the micrograph (Fig. 6), in which two acoustic 
phenomena, emulsification and cavitation, are responsible, in combination; this provokes the crosslinking of the protein shell.

\section{Sonogels}

As already stated, the sol-gel process is based on the possibility of forming the disordered oxide network by various reactions in a liquid phase, followed by solvent elimination. One of the approaches to forming the initial gel is the "alkoxide method". The precursors used in this case are metal alkoxides $\mathrm{M}(\mathrm{OR})_{\mathrm{n}}$, where $\mathrm{M}$ is a metal and $\mathrm{R}$ an alkyl group. These compounds react with water, in the presence of any acid or basic catalyst, and undergo hydrolysis and polycondensation reactions, which lead to the formation of the metal oxide. The polymerization leads first to a colloidal dispersion of particles, the aggregation of which will form the gel when the percolation level is accomplished, forming a coherent solid structure immersed in a fluid medium.

To obtain nanostructured metal oxides using the action of high power ultrasounds to promote the chemical reactions, the "sonogel" method can be used. This procedure avoids the need to use a common solvent for the alkoxide and water mixture $[59,60]$. The acoustic wave effect on the liquid mixture acts in two ways: firstly, the alkoxide/water mixture is emulsified and diffusion between the two phases takes place; secondly, chemical reactions take place in the small bubbles (hot spots) generated by cavitation. The two acoustic processes take place inside the bubbles dispersed throughout the liquid, and the rapid compression/decompression of the ultrasonic wave $(20 \mathrm{kHz})$ causes the bubble radius to oscillate around some equilibrium size and finally to collapse.

When high-power ultrasound is used ( $100 \mathrm{~W}$ output power), extremely hot spots are formed in the liquid in its three discrete stages: nucleation, growth, and implosive collapse [61, 62]. The extreme conditions generated on bubble collapse lead to the production of excited states, breakage of chemical bond, and formation of free radicals. Thus, three areas can be identified in a cavitation system. The center of the hot spot is where the primary chemistry involved in atomic and radical recombination takes place [54]. The surrounding heterogeneous liquid is relatively unaffected, although active molecular species generated inside the bubble may diffuse out and react with reagents in the liquid. At this point, the interfacial region has very large gradients of temperature, pressure, surface tension, electrical field, shear stresses and rapid motion of molecules, leading to efficient mixing $[55,63]$. It is interesting to note that the presence of foreign particles enhances the cavitation because they act as nucleation sites.

The temperature inside the hot-spot increases suddenly as a consequence of the adiabatic bubble collapse, and has been estimated at several thousand degrees Kelvin [64, 65]. The alkoxidewater mixture involved in sonogels can be classified, under Luche's rule [55], as a heterogeneous 
system in which ionic reactions are stimulated inside the cavitation bubbles; therefore the product of the reaction will be the same as it would be in the absence of ultrasound (as by classic or conventional processes). The application of ultrasound to the synthesis of organosilane and organosiloxane precursors has been studied by Boudjouk [66] and Price et al. [67].

\subsection{Pure Silica Sonogels}

This section describes the systematic studies carried out on silicon alkoxide+water mixtures. The aim of such work was to elucidate the differences between sonogels and gels obtained by the conventional (classic) method. As the first parameter involved is the absence of alcohol, one can expect to obtain denser sono-sols due to a lower dilution and, in consequence, a fast polymerization process.

Tarasevich first reported observation of the TEOS/water mixture reaction under the action of high-power ultrasound in 1984 [68]. He reported that the reaction shows an intense increase in temperature with the release of alcoholic vapours. He obtained a homogeneous and transparent solution in a few minutes. Later, Zarzycki's group in France began intensive work to establish the consequence of ultrasound influence on the textural characteristics of "sonogels" [69, 70, 71]. Following this line of research, Esquivias' group in Spain used sonogels as matrices to encapsulate semiconductor nanocrystals [72, 73], organic dyes [74, 75], and OIHMs based on Ormosil [76, 77, 78]. In recent years, Mackenzie's group in the United States has applied the ultrasound method to synthesize OIHMs based on PDMS and TEOS mixtures [65, 79,]. The combined effect of sonocatalysis and organic-inorganic hybrids has opened new routes to nanostructured materials. Pure silica sonogels have also been studied in depth by Donatti, Vollet and Ibañez Ruiz, in Brazil. They report a systematic study on the hydrolysis of TEOS/water and TMOS/water liquid mixtures under the action of ultrasounds, proposing a dissolution reaction model based on dynamic calorimetric measurements $[80,81,82]$. The results are thermally activated hydrolysis with an apparent activation energy of $36 \mathrm{~kJ} / \mathrm{mol}$. From this, the action of ultrasound can be explained as follows: ultrasound forces the dissolution and the reaction begins; the products (alcohol, water and silanol) help to continue the dissolution, with the reaction being dependent on catalyst content, bath temperature and alkyl group length [83, 84].

\subsubsection{Sonocatalysis.}

The corresponding mixture of the silicon alkoxide and acidified water $(\mathrm{pH}<1)$ was placed in a double-volume beaker. No reaction was observed when a neutral or basic catalyst was used. A two-phase system, as shown schematically in Fig. 7, could be discerned in the beaker. At this point the tip of the ultrasonic device was immersed some millimetres into the liquid. The ultrasonic waves 
$(20 \mathrm{kHz}, 60-100 \mathrm{~W})$ are then produced by an electrostrictive device equipped with a stainless steel horn terminated with a titanium tip

Popular choices used in the preparation of silica-based gels are tetramethoxysilane, $\mathrm{Si}\left(\mathrm{OCH}_{3}\right)_{4}$, and tetraethoxysilane, $\mathrm{Si}\left(\mathrm{OC}_{2} \mathrm{H}_{5}\right)_{4}$, known as TMOS and TEOS, respectively. Since these compounds and water are immiscible, a common solvent (usually methyl or ethyl alcohol) has to be added to obtain an initially-homogeneous liquid. However, no solvent is necessary when high-power ultrasound is applied to the liquid mixture. The chemical reactions involved can be summarised as follows:

$$
\begin{aligned}
& \text { hydrolysis } \left.\left.\left.\quad \mathrm{Si}(\mathrm{OR})_{4}+4 \mathrm{H}_{2} \mathrm{O} \quad \rightarrow\right)\right)\right) \text { us } \quad \mathrm{Si}(\mathrm{OH})_{4}+4 \mathrm{ROH} \\
& \text { polycondensation a) } \left.\left.\left.\quad \mathrm{Si}(\mathrm{OH})_{4}+\mathrm{Si}(\mathrm{OR})_{4} \quad \rightarrow\right)\right)\right) u s \quad 2 \mathrm{SiO}_{2}+4 \mathrm{ROH} \\
& \text { b) } \left.\left.\left.\mathrm{Si}(\mathrm{OH})_{4}+\mathrm{Si}(\mathrm{OH})_{4} \rightarrow\right)\right)\right) u s \quad 2 \mathrm{SiO}_{2}+4 \mathrm{H}_{2} \mathrm{O}
\end{aligned}
$$

where $\mathbf{R}$ is $-\mathbf{C H}_{3}$ in the case of TMOS, and $-\mathbf{C H}_{2}-\mathbf{C H}_{3}$ for TEOS. Hydrolysis and polycondensation can be accelerated or slowed down by employing an appropriate acid catalyst. These reactions proceed simultaneously and are generally incomplete. Depending on the amount of water present, hydrolysis may go to completion or stop while the metal is only partially hydrolyzed. On the other hand, the polymerization can be made reversible because silica solubility increases for small particles or small negative curvature (spheres or "necks"). This process gives a strengthened network because the small particles dissolve and are deposited on the larger ones and in the "necks" between two larger particles.

When several different cations are used to form mixed-oxide networks, an initial complexing step may be required. When the alkoxide precursors have different hydrolysis rates (e.g. Al, Zr, Y or Ti, compared with $\mathrm{Si}$ ), prehydrolysis of the alkoxysilane is preferred [59]. After a complex sequence of polymerization, sol formation and gelation, a microporous gel with high surface area is formed, constituted by small particles; its formula is approximated by:

$$
(\mathrm{MO})_{\mathrm{x}}\left(\mathrm{M}^{\prime} \mathrm{O}\right)_{\mathrm{x}} \cdot(\mathrm{OH})_{\mathrm{y}}(\mathrm{OR})_{\mathrm{z}}
$$

The radicals $-\mathrm{OH}$ and $-\mathrm{OR}$ account for reaction by-products that can, reasonably easily, result in a system that yields a complex three-dimensional oxide -M-O-M'-O-M- polymer which preconfigures the network of corresponding oxide glasses.

In the case of copolymerization between (organic) PDMS and (inorganic) TEOS, the reaction proceeds as follows, in order to form the hybrid organic-inorganic network: 
The $\mathrm{n}$ value determines the polymer chain length and leads to the desired the physical properties by the interconnecting of silica particles through the polymer chain cross-links.

Continuing with the effects of ultrasound, the ultrasonic energy delivered to the solution can be estimated by the temperature increase of a fixed volume $(\mathbf{V})$ of water during the sonic treatment, and consequently can be calculated by the relationship:<smiles>CC(O)(O[Si](C)(C)C(C)(C)O[SiH3])[Si](C)(C)O</smiles><smiles>CC(C)([Si](C)(C)O[Si](O)(O)O)[Si](C)(C)O[Si](O)(O)O</smiles>

$$
W=\frac{d Q}{d t}=m \cdot c \frac{d T}{d t}
$$

where $\mathbf{d T}$ /dt is the rising slope in the experimental curve of Fig. 8. The mass of water and its specific heat are $\boldsymbol{m}$ and $\boldsymbol{c}$ respectively. Then the energy delivered by the ultrasound will be:

$$
U_{s}=\frac{W \cdot t}{V} \approx K \cdot t\left(J \cdot \mathrm{cm}^{-3}\right)
$$

where $\mathbf{t}$ is the sonic treatment time in minutes and $\mathbf{K}$ is a constant characteristic of the apparatus. Many factors can affect these $\mathbf{K}$ values, such as room temperature, thermostatic bath temperature, catalyst content, molar ratios of water/alkoxide or solvent/alkoxide, beaker diameter and volume, depth of horn tip immersion in the liquid solution and tip diameter, among others.

Once the liquid mixture reacts and a homogeneous solution is observed, the energy dose is taken as the threshold of the hydrolysis reaction. Also there is an energy dose at which the liquid gels "in situ"; that is, gelation takes place in the beaker during the ultrasonic treatment. At this point, a transparent soft solid gel, with the tip hole on top, can be observed. Between these two limits one can tune the gelation at any particular dose within the energy range. As a reference, some of these energy doses, $\mathbf{U}_{\mathbf{s}}(\min )$ and $\mathbf{U}_{\mathbf{s}}(\max )$, are shown in Table $\mathbf{1}$ for different precursors and contents. In this way, if the minimum dose is related to the hydrolysis reaction, as can be seen in Table 1, the expected decrease of the hydrolysis rate due to the dilution is compensated by the 
action of ultrasound. At the other limit, the maximum dose that can be related to the polycondensation rate produces greater reactivity of the TMOS. However, this effect is reduced by the presence of the PDMS organic polymer. This fact could be a consequence of the different functionality of the precursors, $\mathbf{f}=4$ for TEOS and TMOS and only $\mathbf{f}=2$ for PDMS.

Table 1.- Threshold and limiting of the ultrasonic energy dose.
\begin{tabular}{|c|c|c|c|c|}
\hline $\mathrm{U}_{\mathrm{s}}\left(\mathrm{J} \mathrm{cm}^{-3}\right)$ & $\begin{array}{c}\text { TEOS/water } \\
4\end{array}$ & $\begin{array}{c}\text { TEOS/water } \\
(\text { PDMS }) \\
2\end{array}$ & $\begin{array}{c}\text { TMOS/water } \\
\text { TMOS/water } \\
(\text { PDMS }) \\
2\end{array}$ \\
\hline $\mathrm{U}_{\mathrm{s}}(\min )$ & 80 & 60 & 70 & 40 \\
\hline $\mathrm{U}_{\mathrm{s}}(\max )$ & 1360 & 1100 & 350 & 1000 \\
\hline
\end{tabular}

Once the sonosol has been exposed to the corresponding ultrasonic energy dose, the liquid sonosol is kept in a hermetic container and allowed to gel at the chosen temperature. Since the sonosol is a low-viscosity liquid, it can be cast in a mould with a selected shape. In all cases, for the silicon alkoxides, a homogeneous and transparent solution is obtained due to the fine dispersion of the colloidal particles formed, which begin to aggregate to produce the so-called nanostructured sonogel.

\subsubsection{Sonogel Gelation}

The point at which the sol passes from a viscous fluid to an elastic solid is taken as the gelation point. At this point the viscosity increases abruptly by several orders of magnitude. The gelation time is taken as the time interval between the end of the ultrasonic treatment and the abovementioned transition. This transition can be estimated visually when the solution surface is no longer horizontal when the container is tilted.

Fig. 9 shows the results of the gelation time $\mathbf{t}_{\mathbf{G}}$ as a function of $\mathbf{U}_{\mathbf{s}}$ for a molar ratio of $\mathrm{H}_{2} \mathrm{O} / \mathrm{TEOS}=4$, at several mixture temperatures. In fact, the temperature, as well as the increase in the ultrasonic energy dose, both activate the gelation process. As can be observed, two regimes are present, separated by a level of $\mathbf{U}_{\mathrm{s}}=600 \mathrm{~J} \mathrm{~cm}^{-3}$. This point indicates the rapid increase in the polycondensation rate. As a reference for classic gels, the gelation time is of the order of several days for similar compositions, and is dependent on solvent content.

From the experimental values of Fig. 9 it is possible to establish the thermal behaviour of the gelation process. The plot of $\mathbf{t}_{\mathbf{G}}$ vs. 1/T is depicted in the inset of Fig. 9 for different ultrasonic energy doses. Assuming an Arrhenius behaviour, the corresponding linear fit gives an activation 
energy of 50-70 $\mathrm{kJ} \mathrm{mol}^{-1}$ TEOS, which is of the same order of magnitude as the results reported by Tiller et al. [85], $45 \mathrm{~kJ} \mathrm{~mol}^{-1}$ TEOS. The $\mathrm{pH}$ dependence of the activation energy, that is, the activation energy obtained for sonogels, agrees with the results reported by Coudurier et al. [86], of $61 \mathrm{~kJ} \mathrm{~mol}^{-1}$ for the condensation process, and $63 \mathrm{~kJ} \mathrm{~mol}^{-1}$ for the aggregation process. This indicates that the polycondensation in pure sonogels is achieved mostly in the early stages, producing a more reticulated structure than in classic processes.

Similar results are obtained for a sol of $90 \%$ wt TEOS $+10 \%$ wt PDMS and a molar ratio $\mathrm{H}_{2} \mathrm{O} /$ TEOS $=2$, in which the two regimes can also be observed. However in this case hybrid materials are separated by a level of $U_{\mathrm{s}}=450 \mathrm{~J} \mathrm{~cm}^{-3}$, accounted for by the influence of the PDMS organic polymer. This effect may be due to the chain breaking as a consequence of the ultrasound cavitation, preventing the formation of rings. In fact, in the first regime, pure sonogels are obtained twice as fast, and in the second, three times as fast as the hybrid gels. Since the reactions in the PDMS/TEOS hybrid system are more complex than those in pure silicon alkoxides, the activation energy is difficult to calculate. Mackenzie and Hoshino report a value of $60 \mathrm{~kJ} \mathrm{~mol}^{-1}$ for a $20 \% \mathrm{wt}$ PDMS Ormosil [87], which is similar to that of pure silica sonogels, revealing the relatively minor influence of the temperature in this process, compared with that of the ultrasound applied.

\subsubsection{Sonogel drying}

Two methods are used to dry the wet sonogel:

1) A process of slow evaporation or the use of a chemical additive (DCCA), which give a very shrunk solid called a sono-xerogel, in which the syneresis and permeability collapse the gel microstructure.

2) Venting off a supercritical solvent, which produces a solid known as a sono-aerogel, in which the original microstructure of the gel is preserved.

The process of drying requires several steps; first, after gelation, the gel solid network shrinks by an amount equal to the volume of liquid that evaporates and the liquid-vapour interface remains outside of the solid. The second stage begins when the gel stops shrinking and the liquid is expelled from the pores. At this stage, capillary forces take effect to shrink the solid network, and pressure gradients can produce cracking in the solid. Differential stresses between adjacent pores provoke fracture of the solid if the tensile strength of the material is exceeded. This behaviour can be seen in accordance with the formula of Laplace for the capillary pressure for a pore of radius $\mathbf{r}$ :

$$
\Delta p=\frac{2 \gamma \cos \theta}{r}
$$

where, $\gamma$ and $\boldsymbol{\theta}$ are the liquid specific surface energy and its wetting angle, respectively. In the case of a pore of $2 \mathrm{~nm}$ radius filled with water $\left(\gamma=0.073 \mathrm{~N} \mathrm{~m}^{-1}\right)$ with perfect wetting $(\cos \theta=1)$, a pressure 
of $73 \mathrm{MPa}$ is generated. There are several strategies for preventing these stresses: one is to add a chemical additive (DCCA) to the precursor liquid mixture, before gelling, to control the drying [88].

The additive most commonly used as a DCCA is the protic solvent formamide $\left(\mathrm{HCONH}_{2}\right)$ [89]; the bonding of hydrogen to hydroxyl ions reduces the catalytic activity and influences both the hydrolysis and condensation reactions. The influence of formamide as the DCCA is a consequence of its low vapour pressure and surface tension. The reduction in the capillary pressure is accomplished by the formation of a film on the pore wall, reducing the contact angle and the solvent evaporates very slowly, providing a plasticizing effect. The success of this method can be attributed to the coarsening of the microstructure and the strengthening of the gel network. Other solvents that are effective in this application include dimethyl formamide (DMF) [90], oxalic acid and glycerol [91], among others.

The other strategy for maintaining the original microstructure of the gel as it exists at the gelation point is by supercritical drying. When the critical point of one liquid is surpassed, there are no distinctions between liquid and vapour phases and their densities become equal (as a supercritical fluid); then capillary pressure stops and the permeability decreases. To achieve this, the wet gel is placed in an autoclave and the temperature and pressure are raised up to the critical point of the corresponding solvent, taking care not to cross the liquid-vapour boundary; then the solvent is vented isothermally. The critical points of various solvents are shown in Table 2 . The gel obtained is a solid network with the pores filled by air, termed an aerogel.

The experimental process is crucial for maintaining the solid in one monolithic piece, so the ramp or gradient applied to raise the temperature must be as slow as possible $\left(<1^{\circ} \mathrm{C} / \mathrm{min}\right)$ because of the differences in the thermal expansion coefficients of the liquid and solid. This difference gives rise to pressure gradients and can cause the solid gel to crack. It is also common practice to apply the extra pressure of an inert gas from the beginning, in order to avoid crossing the liquid-vapour boundary. In the case of a volatile solvent, one disadvantage is the high temperature necessary (Table 2); the use of $\mathrm{CO}_{2}$ permits the process to be performed at near ambient temperature. This process was first applied by T. Woignier [92] and Tewari et al. [93]. Supercritical drying needs the pore liquid (alcohol+water) to be replaced by liquid $\mathrm{CO}_{2}$; a complete solvent exchange is necessary because capillary compression is produced by the immiscible boundary between water and $\mathrm{CO}_{2}$. The main application found this method is in the preparation of organic-inorganic hybrid aerogels because it prevents degradation of the organic polymer by temperature.

Another approach is to freeze the pore liquid and sublime the resulting solid under vacuum, which is termed freezing-drying [94]; though this is widely used in the preparation of foods, it does not permit the preparation of monolithic pieces. 


\subsection{NanoStructure of dry silica sonogels.}

The special characteristics of sonogels must be due to the solid network nanostructure, therefore it is important to study this structure using various characterization techniques.

From an atomic point of view, the average number of atoms per unit length situated at a distance $r$ from an arbitrary atom taken as a reference is given by the radial distribution function $\operatorname{RDF}(r)=4 \pi r^{2} \rho(r)$, where $\rho(r)$ is the local atomic density, given by the relationship [95]:

$$
4 \pi r^{2} \rho(r)=4 \pi r^{2} \rho_{0}+\frac{2 r}{\pi} \int_{0}^{\infty} k i(k) \sin k r d k
$$

where $k=\frac{4 \pi \sin \theta / 2}{\lambda}$ is the scattering vector modulus with $\theta$ the scattering angle, $\lambda$ the $X$-ray wavelength, $\mathbf{k i}(\mathbf{k})$ are the reduced X-Ray experimental intensities and $\boldsymbol{\rho}_{\mathbf{0}}$ is the macroscopic density. To avoid spurious oscillations due to the cut-off in the Fourier transform, data were extended up to $5 \mathrm{~nm}^{-1}$ by the method proposed by D'Anjou and Sanz [96].

The RDF's first peak position indicates the most probable distance of the first neighbours. The reduced RDFs for a sonogel, a classic gel, and silica glass are represented in Fig. 10; this magnitude represents the deviation of the RDF from a uniform distribution, $4 \pi \mathbf{r}^{2} \rho_{0}$. The average bond length found was the same for both sono and classic gels, $0.002 \mathrm{~nm}$ longer than in silica glass, as can be seen in Table 3. The average atom coordination in silica sonogels is very near that of bulk silica glass. Fig. 10 shows another important finding, a correspondence between sonogel and silica bulk glass in respect of the RDF maxima up to $\mathbf{r}$ at around 1.1-1.2 nm. Beyond this distance this correspondence is lost abruptly. In the case of the classic gel the deviation occurs more gradually. These differences are interpreted to mean that sonogels are formed by monosized elementary particles of $\sim 1 \mathrm{~nm}$ radius, whereas the classic gel is formed by particles with a larger size and a wider size distribution.

The skeletal density of the solid backbone can be calculated from the RDF(r). This was evaluated by the maximum entropy method (MEM) [97, 98], which gives the RDF of an arrangement of atoms as the one corresponding to the atomic distribution compatible with X-ray diffraction data. The RDF was found to be compatible with the experimental data and, in particular, with the solid backbone density. The macroscopic atomic density of both sono- and classic silica aerogel was found to be $\rho_{0}=63.0 \pm 0.5$ atom $/ \mathrm{nm}^{3}$ and for pure silica glass, used as a reference, the resulting comparable density value is $\rho_{0}=66.0 \pm 0.5$ atom $/ \mathrm{nm}^{3}$ (Table 3). These differences are derived from the presence of non-bridging oxygen atoms (NBOs) at the pore-matrix interface in the aerogels, which also cause the lengthening of the average Si-O bond [99]. 
A first approximation to the number of NBOs can be made from the area beneath the first RDF peak, A, which is related to the average number of atoms in the first coordination sphere by the relationship [100]:

$$
A=\frac{1}{\left(\sum \mathbf{x}_{\mathrm{i}} \mathbf{Z}_{\mathrm{i}}\right)^{2}} \sum \sum \mathbf{x}_{\mathrm{i}} \mathbf{Z}_{\mathrm{i}} \mathbf{Z}_{\mathbf{j}} \mathbf{n}_{\mathrm{ij}}
$$

where $\mathbf{Z}_{\mathbf{i}}$ is the $\mathbf{i}$-element atomic number, and $\mathbf{n}_{\mathbf{i j}}$ are the averaged number of $\mathbf{j}$-type atoms in the first coordination sphere of an i-type atom and is calculated from the hypothesis formulated. In this case the hypothesis is that each atom has its bonds satisfied except for a fraction $\alpha$ of oxygen atoms, $0<\boldsymbol{\alpha}<1$ and rejecting any O-O and Si-Si bonds, that is $\mathbf{n}_{11}=\mathbf{n}_{22}=0, \mathbf{n}_{12}=4$ and $\mathbf{n}_{21}=2-\boldsymbol{\alpha}$, giving $\mathbf{A}=2.99-0.747 \boldsymbol{\alpha}$. This expression for $\mathbf{A}$ was compared with the experimental values in Table 3, giving values of $\mathrm{NBO}_{\text {sono }} \cong 8 \%$ and $\mathrm{NBO}_{\text {classic }} \cong 16 \%$. According to these values, the sonogel atomic network is more reticulated than that of classic gels. The sonogel route gives an atomic short-range order closer to that of bulk silica glass.

These results support the results of the ${ }^{29} \mathrm{Si}$ MAS-NMR (Fig. 11), which indicate that the sonogel structure (S2 and S6) is more cross-linked than that of gels obtained in alcohol solution (C2 and C6), termed classic gels. The spectra are interpreted by means of the $\mathrm{Q}_{\mathrm{n}}$ component which denotes the number $\mathbf{n}$ of bridging oxygens (-OSi) surrounding a central silicon. The chemical shift $(\boldsymbol{\delta})$ is referenced to the tetramethylsilane (TMS) and give a measure of the deviation of the chemical environment of each $\mathrm{Si}$ atom. The different signal components are identifiable as $\mathrm{Q}_{2}$ at $\delta=-89 \mathrm{ppm}$, $\mathrm{Q}_{3}$ at $\delta=-100 \mathrm{ppm}$ and $\mathrm{Q}_{4}$ at $\delta=-109 \mathrm{ppm}$, approximately. The absence of a $\mathrm{Q}_{1}$ component indicates that alkoxide monomers are not present. However, the existence of incomplete Si-O-Si bridges in the gels $\left(\mathrm{Q}_{2}\right.$ and $\mathrm{Q}_{3}$ components) indicates the existence of $-\mathrm{OH}$ surface covering radicals. The $-\mathrm{OH}$ content will be relative to the peak intensities and gives similar values for both sono- and classic gels $(\sim 0.53 \mathrm{OH} / \mathrm{Si})$, which account for the linear polymer-like structure, the entanglement of which can form the elementary particle. In this way superficial $-\mathrm{OH}$ content can be calculated assuming a model of non-contacting spherical particles of $1.1 \mathrm{~nm}$ radius taking into account the specific surface area from BET physisorption measurements. By this calculation the results for S2 and S6 samples were 4.0 and $4.6 \mathrm{OH} / \mathrm{nm}^{2}$, respectively, whereas for the samples C2 and C6 the results were 7.8 and $8.0 \mathrm{OH} / \mathrm{nm}^{2}$, respectively. In agreement with the conclusions from the RDF results, the classic gels have higher $\mathrm{OH}$ surface coverage. Thus sonogels form a more cross-linked and homogeneous nanostructure.

In addition, the solid backbone and pore structure have been studied over a wide range of lengthscales, using small-angle X-ray scattering (SAXS) [101, 102] and gas physisorption; specific 
surface area is calculated by the BET method [103] and pore size distribution (PSD) from the BJH method [104].

The scattered intensities $(\mathbf{I}(\mathbf{q}))$ in a scattering experiment are given as a function of the scattering vector modulus $q=\frac{4 \pi \sin (\theta / 2)}{\lambda}, \theta$ is the scattering angle and $\lambda$ is the radiation wavelength. Its physical meaning is the momentum transfer from the incident to scattered wave. Measuring the scattered intensity at momentum transfer $\mathbf{q}$ is equivalent to analyzing the real space density distribution with a spatial resolution of $\mathbf{2} \pi / \mathbf{q}$.

From the general treatment of SAXS data, in a standard log-log plot, three regions can be discerned:

a) Guinier region. This corresponds to the low $\mathbf{q}$ region, where $\log \mathbf{I}(\mathbf{q})$ is almost constant. The analysis can be approximated by Guinier's law, which provides information about the overall size of scatterers:

$$
\mathbf{I}(\mathbf{q})=\mathbf{I}(\mathbf{0}) \exp \left(-\frac{\mathbf{R}_{\mathrm{g}}^{2} \mathbf{q}^{2}}{3}\right)
$$

where $\mathbf{I}(\mathbf{0})$ is the intensity at $\mathbf{q}=0$, and $\mathbf{R g}$ is the gyration radius of the aggregates. $\mathbf{R g}$ is calculated from the linear regression in a $\ln \mathbf{I}(\mathbf{q})-\mathbf{q}^{2}$ plot (Guinier's plot). In dilute systems, $\mathbf{R g}$ gives the characteristic particle size. In dense systems, it gives a correlation length above which the system can be considered homogeneous whenever $\mathbf{R g} \cdot \mathbf{q}<\mathbf{1}$. The Guinier's plot also provides, by extrapolation, $\mathbf{I}(\mathbf{0})$ from which a correlation volume,

$$
V_{C}=2 \pi^{2} I(0) / Q_{0}
$$

can be estimated. This is a geometrical parameter related to the average volume occupied by the scattering centres, and $\mathbf{Q}_{\mathbf{0}}=\int_{0}^{\infty} \mathbf{I}(\mathbf{q}) \mathbf{q}^{2} \mathbf{d q}$ acts as a normalizing factor; this is known as Porod's invariant and is independent of the scatterer's geometrical shape. If we assume a spherical geometry for this volume, a sphere of radius $\mathbf{r}$ can be calculated $\left(\boldsymbol{R}_{g}^{2}=\frac{\mathbf{3}}{\mathbf{5}} \boldsymbol{r}^{2}\right)$.

b) Fractal region. This is obtained for $1 / \mathbf{R g}<\mathbf{q}<1 / \mathbf{a}$, with a being the elementary particle size. $\mathbf{I}(\mathbf{q})$ exhibits a power-law as: $\mathbf{I} \propto \mathbf{q}^{-\mathbf{D}}(\mathbf{D}<\mathbf{3})$ over more than one order of magnitude [105, 106]. This means that the material has a mass fractal of dimension $\mathbf{D}$ that can be calculated from the slope of the corresponding straight region in the $\log \mathbf{I}-\log \mathbf{q}$ plot; in this way $\mathbf{D = 3}$ will be a sphere (Euclidean). The fractal dimension can be interpreted in terms of structure and is a consequence of the growth and kinetic mechanism of the aggregation process. In this interpretation the intricate 
structure of the porous silica gels is the consequence of a cluster-cluster aggregation, either by diffusion-limited (DLA) or by reaction-limited (RLA), as reported by several authors [107, 108, 109, 110]. However in the case of sonogels, given their homogeneous and narrow size distribution, this concept is meaningless.

c) Porod's region. For a large enough value of $\mathbf{q}, \mathbf{I}(\mathbf{q})$ tends progressively to a $\mathbf{q}^{-4}$ power law when the particles are smooth with a well-defined interface. In the presence of a surface fractality, which occurs on rough surfaces, the slope of the $\log \mathbf{I}-\log \mathbf{q}$ plot would be $\mathbf{q}^{-(\mathbf{6}-\mathbf{D S})}$ power law, where $\mathbf{2}<\mathbf{D}_{\mathbf{S}}<\mathbf{3}$ is the surface fractal dimension, where $\mathbf{D}_{\mathbf{S}}=\mathbf{2}$ represents a smooth or flat surface (Euclidean). Mass and surface fractals are never found on the same length scale.

Porod's limiting law states that:

$$
\lim _{\mathbf{q} \rightarrow \infty}\left(\mathbf{q}^{4} \mathbf{I}(\mathbf{q})\right) \rightarrow \frac{S}{V} \frac{\mathbf{Q}_{0}}{\pi}
$$

where $\mathbf{S}$ is the surface and $\mathbf{V}$ is the volume of the particles. In the case of a dense system, this ratio gives an estimate of the specific surface $\mathbf{S} / \mathbf{V}$ of the system. Between these regions, a progressive transition, called a cross-over, is observed. Thus, $\mathbf{q}=\mathbf{q}_{\mathbf{m}} \approx \mathbf{1} / \mathbf{R}_{\mathrm{g}}$ is the cross-over between Guinier and fractal regions. The position $\mathbf{q}_{\mathbf{m}}$ of the cross-over between fractal and Porod's region defines the size $\mathbf{R}^{\prime}=\mathbf{1} / \mathbf{q}_{\mathbf{m}}$ of the primary particles, which form the fractal aggregates. Sometimes the cluster aggregation in this kind of solid shows a deviation from Porod's law [111, 112] giving the behaviour: $\lim \left[\mathbf{I}(\mathbf{q}) \mathbf{q}^{\mathbf{4}}\right]=\mathbf{A}+\mathbf{B} \mathbf{q}^{\mathbf{4}}$, where the parameter $\mathbf{B}$ is associated with the electronic density fluctuation due to the microporosity. The parameter $\mathbf{A}$, on the other hand, is related to the surface area of the pore-matrix interface and is highly dependent on the surface roughness [113, 114].

In the particular case of sonogels, in the $\log \mathbf{I}(\mathbf{q})$ versus $\log \mathbf{q}$ curves, they present a wide plateau as shown in Fig. 12; this feature reveals the homogeneous distribution of the silica aggregates and, hence, a well-defined gyration radius. Guinier's law (inset of Fig. 12) gives $\mathbf{R}_{\mathbf{g}}=2.8$ and $2.6 \mathrm{~nm}$ for the sono-aerogel and sono-xerogel, respectively. In the low q-region where Guinier's law applies, the classic-gel shows an increase in the scattered intensity produced by large aggregates with an $8.2 \mathrm{~nm}$ gyration radius. The scattering intensity from a sphere of $3.5 \mathrm{~nm}$ radius is also represented, to illustrate that the particles formed in sonogels are near-spherical. In the continuous gel network, discontinuities of the Bessel function at $\mathbf{q} \mathbf{R}=\tan (\mathbf{q} \mathbf{R})$ values are absent.

A SAXS study during gelation shows that the sonogel structure is consistent with a statistical model of packed balls [115]. These tangles of gel compact during ageing and, after drying, give rise to a very homogeneously-packed aggregate formed from $\sim 1 \mathrm{~nm}$ spheroidal particles. The value of $\mathbf{q}$ at which the curve begins to fall from the wide plateau in Fig. 12, indicates the size of the aggregates ( 4-5 nm). Consequently, sonogels have a narrower pore size distribution, higher bulk density, and a surface/volume ratio two or three times higher than gels prepared in 
alcohol solutions. Their very fine and uniform porosity, and high apparent density, in addition to the short gelation time, are unique features of sonogels. These parameters are very sensitive to the ultrasonic dose supplied. The larger the ultrasonic dose, the finer the porosity and the higher the homogeneity. The gelling temperature also affects these parameters. Porod's law applies to both sono- and classic gels. This power law states that $\mathbf{I}(\mathbf{q}) \propto \mathbf{q}^{-4}$ in the high-q region when the poresolid matrix interface is sharp.

Analysis by $\mathrm{N}_{2}$ isotherm is a method used to quantify the pore structure, from the pioneering work of Langmuir [116] relating the gas volume adsorbed to its relative pressure. The method, which assumes only monolayer formation, was later developed for multiple layers by Brunauer, Emmet and Teller, who devised what is known as the BET method. This is now a standard approach for determining the specific surface area by the linear form of the BET equation of the gas volume adsorbed $\mathbf{V}$ as a function of the relative pressure $\mathbf{P} / \mathbf{P}_{\mathbf{o}}$, in the range of 0.05 to 0.3 by the relationship:

$$
\frac{P}{V\left(P_{o}-P\right)}=\frac{1}{V_{m} C}+\frac{(C-1)}{V_{m} C} \frac{P}{P_{o}}
$$

where $\mathbf{V}_{\mathbf{m}}$ is the monolayer volume and $\mathbf{C}$ is a parameter related to the adsorbent-adsorbate interaction. The traditional use of $\mathrm{N}_{2}$ at $77 \mathrm{~K}$ as adsorbate permits the calculation of the specific surface area from $\mathbf{V}_{\mathbf{m}}$ assuming a cross- sectional area for the nitrogen molecule of $0.163 \mathrm{~nm}^{2}$ for oxide surfaces. Different types of isotherms are classified according to the IUPAC [117, 118, 119]. In some cases of mesoporous solids, capillary condensation can lead to the appearance of a hysteresis loop in the adsorption-desorption record, which is produced by both thermodynamic and network effects. These combined effects are derived from the metastability of the condensation or evaporation, which can be delayed; the pore shape and connectivity also play an important role in the desorption process. Pore size and pore size distribution (PSD) can be extracted from the isotherm for a specific pore model, usually based on the Kelvin equation for cylindrical capillary [120]:

$$
r_{k}=\frac{-2 \sigma V \cos \theta}{R T \ln \left(P / P_{o}\right)}
$$

where $\boldsymbol{\sigma}$ is the surface tension of the liquid, $\boldsymbol{\theta}$ the wetting angle, $\mathbf{V}$ the molar volume, $\mathbf{R}$ the gas constant and $\mathbf{T}$ the absolute temperature. In the case of liquid nitrogen the equation takes the form:

$$
r_{k}=\frac{4.416}{\log \left(P_{o} / P\right)}
$$

where $\mathbf{r}_{\mathbf{k}}$ is the capillary radius which fills at a partial pressure of $\mathbf{P} / \mathbf{P}_{\mathbf{0}}$. However, if the diameter of the capillary approaches the molecular dimension, it is necessary to take into account the thickness 
of the adsorbed layer $\mathbf{t}$ on a flat surface, called its statistical thickness. In the case of nitrogen this thickness is:

$$
t=\frac{4.58}{\left[-\log \left(p / p_{0}\right)\right]^{1 / 3}}
$$

then the pore radius is given as $\mathbf{r}_{\mathbf{p}}=\mathbf{r}_{\mathbf{k}}+\mathbf{t}$.

Several algorithms are used to calculate the PSD from the isotherm, such as those proposed by Barret, Joyner and Halenda (BJH), Cranston and Inkley (CI) [121] and Dollimore and Heal (DH) [122], which are among the most commonly used. In these methods the adsorption in mesopores is pictured as a multilayer adsorption followed by capillary condensation which fills the pore core that is not occupied by the multilayer film on the pore wall. On the other hand, the desorption is pictured as capillary evaporation which empties the pore core, with the retention of the multilayer film, following which the thickness of these multilayers is reduced. In the case of microporous adsorption and desorption, a different method proposed by Horvarth and Kawazoe [123] is used; this is based on the assumption that empty pores become completely filled at relative pressures that are related to their size. In this case adsorption proceeds via micropore filling at lower relative pressure, followed by multilayer adsorption and capillary condensation; as a consequence, an abrupt increase of the adsorbed volume is observed. In such cases, from a standard t-plot (adsorbed volume versus statistical thickness $\mathbf{t}$ ), a linear region can be discerned and the contribution of the microporosity to the specific surface area can be extracted.

Sonogels, in the form of xerogels and aerogels, are examples of solids with both microporous and mesoporous structure, respectively. For our samples these features can be seen in Fig. 13; that is, a type I isotherm for the xerogel sample and type IV isotherm for the aerogel. There is adsorption at low pressure in both cases, but not further in the case of the xerogel, and capillary condensation with hysteresis in the desorption branch in the case of the aerogel. In line with the previously reported results, the xerogel is an entanglement of elementary particles of $2.8 \mathrm{~nm}$ radius forming a microporous network of $1.1 \mathrm{~nm}$ pore radius, as indicated in the t-plot in the inset of Fig. 13. The aerogel, however, is formed by particles of $1.7 \mathrm{~nm}$ radius forming a mesoporous network of $2.3 \mathrm{~nm}$ pore radius. The pore size distribution of these samples shows a narrow peak in the micro- and the mesopore regions, respectively. The results illustrate the differences between the collapsed microstructure of the xerogel and the original nanostructure sonogel in the case of the aerogel.

\subsection{Cluster Model: random-packing of spheres.}

Given the above results, a sonogel can be considered a random close packing (RCP) structure constituted by elementary spherical particles of 1-2 nm radius forming clusters of 4-5 nm average radius, which in turn form larger clusters, and so on, in a hierarchical structure. Some 
attempts have been made to depict such hierarchies on several levels, using models constructed with the Monte-Carlo technique [124, 125, 126]. The approach is based on comparing the pore size distribution of sonogels with that of a random close-packed hard sphere model studied by Bernal and Mason [127], Scott [128] and Finney [129], and developed for this application by Zarzycki [130]. The texture of gels is generated on the basis of two critical magnitudes: the compactness of the packing $\mathrm{C}=($ volume of spheres)/(total volume), and the average coordination number $\mathrm{CN}$, almost linearly related by $\mathrm{CN} \approx 12.7 \mathrm{C}$ with a maximum at 8 , depending on the closeness of the contact. This parameter, closeness of contact, is given by the centre-to-centre to sphere diameter ratio (L/d), in order to identify when two spheres are coordinated. The pore size distribution (PSD) is then considered as the volume of the largest sphere the radius of which can be inscribed in the interstices. The models considered are not purely geometric since the models were subjected to different processes of relaxation and hollowing out. A catalogue of PSD models has been created, against which the experimental PSD of the gel in question is compared, to choose the most realistic model. The convergence of the models is performed by introducing random voids into the structure and relaxing by a Lennard-Jones potential [131]; the minimum energy distribution is found using a Monte-Carlo algorithm. Some of these models and their PSD are shown in Fig. 14 for the various different values of $\mathrm{L} / \mathrm{d}$ ratio and $\mathrm{C}$ given in Table 4.

Another approach considers the structure of an aerogel as an assembly of randomly-packed spherical particles in several hierarchically-ordered levels [125,130,132,133]. Knowledge of the aerogel structure has been acquired using computer simulation techniques taking inputs from several sources, such as a better understanding of the sol-gel process. Several studies of the structure formation process have used the Molecular Dynamics Technique [134]; this was first applied by Garofalini and col. to the sol-gel process in 1994 [135] using the Feuston-Garofalini potential [136]; they concluded that the structure formation starts with a process of slow growth of the individual clusters, followed by the faster growth of the structure due to cluster-cluster aggregation.

It is generally accepted that the Cluster-Cluster Aggregation regimes (DLCA - DiffusionLimited Cluster Aggregation, RLCA - Reaction-Limited Cluster Aggregation) describe quite well the typical structures obtained via sol-gel. One of the goals pursued most by researchers is to reproduce the formation and growth processes of aerogels, using the RLCA or DLCA algorithms or some modifications of these [137,138]. Scherer and col. [139] used structures generated with modified DLCA algorithms, characterising them by their fractal dimension, to achieve the power law exponent, and they have presented several models to explain the relationship between structure and mechanical properties [140,141]. Since then, Woignier and col. have introduced a new technique for characterising these porous systems [142,143], and conclude that pore size 
distribution and hydroxyl content are relevant for understanding the mechanical properties of these materials [144]. In a previous study, Woignier and Phallipou proposed one approach starting from a cubic structural model [145] and for a rigid assembly of cohesive spheres [146]. The Cluster Model that is introduced here has also been applied as an initial approach to the study of mechanical properties [133].

The diagram shown as-in Fig. 15a explains the process of construction. The algorithm works as follows: first we place one elementary sphere in the centre of our system. Then we randomly place as many other spheres as are needed to cover fully the surface of the first one; this produces the first random shell. Every sphere has to be in contact with at least one other; that is, the sphere centres must be at a previously defined distance from each other. One can build as many shells of randomly-placed spheres as are required. This shell then constitutes the basic aggregate of the first hierarchical level, and its diameter is measured. This diameter will be taken as the diameter of a secondary sphere.

The next level in the hierarchy is constructed in the same way, treating the basic aggregate as if it were an elementary sphere to construct the second level with secondary spheres. After constructing this new aggregate, each secondary sphere forms a new basic aggregate, to obtain a two-level hierarchically-ordered assembly of randomly-packed spheres. This process can be repeated as many times as required. Typical values of our models are 1000 to 60,000 particles organised in 2 to 4 shells of randomly-packed spheres and 2 or 3 hierarchical levels; their contact distance $L$ usually is found in the interval $0.85 \mathrm{~d}<L<1.0 \mathrm{~d}$, $\mathrm{d}$ being the particle diameter.

A sketch of a cluster model can be seen in Fig. 15b rendered using the free software POVRay [147]. The system illustrated corresponds to the simulation box cropped from model \#2, and has around 3000 particles [148]. We have built several cluster models that represent the microstructure of various real systems. Table 5 gives the characterization parameters of some real systems and their corresponding models. Systems \#1 and \#2 correspond to two different silica aerogels prepared from TEOS, and were characterized by the analysis of the $\mathrm{N}_{2}$ adsorption/desorption isotherms [149]. These results confirm the good agreement between the Cluster Model and the actual nanostructured sonogel.

\section{Nanocomposites from sonogels.}

Nanocomposites are materials in which the constituents are mixed on a nanometer scale to give properties that are superior to conventional microscale composites. They can be synthesized by a variety of techniques including the sol-gel process and, more specifically, by using ultrasound. This produces cavitation in the liquid sol, which in general leads to the matrix phase, as an 
additional parameter for controlling the mixing at the nanometer length scale with the secondary phase.

Considerable research has been devoted to this type of material since 1989, covering different phases, designs, morphologies and technological uses, to produce ceramic [150,151] and optoelectronic [152,153] materials and polymers [76]. Hybrid aerogel nanocomposites made from sonogels, with the incorporation of a second and active phase, have found applications as bioactive materials [154,155] and for $\mathrm{CO}_{2}$ sequestration $[156,157]$.

\subsection{Nanocrystals embedded in a sonogel matrix.}

Adopting the sonosol liquid stage at the early stages of the process also favours the formation of nanocrystals with uniformity in composition, shape, size, internal structure and surface chemistry, which are essential characteristics for designing and controlling the behaviour of materials. In this field, materials containing semiconductor nanocrystallites immersed in a dielectric matrix have attracted great interest because they display third-order optical non-linearities and dramatic changes in the optical absorption spectra with respect to the conventional bulk semiconductor [158]. A II-VI semiconductor such as CdS has been studied in detail because it precipitates easily in a silica gel matrix to give good optical transmission. The sonocatalytic method has been proven suitable for preparing silica matrices for fine and uniform dispersion of $\mathrm{CdS}$ quantum dots (QDs) [152]. The silica sono-xerogels were prepared by ultrasound-assisted hydrolysis of a mixture of tetramethoxysilane (TMOS):acid water:Formamide, in the molar ratio 1:10:3, using an ultrasound dose of $64 \mathrm{~J} \cdot \mathrm{cm}^{-3}$. Different amounts of $\mathrm{Cd}\left(\mathrm{NO}_{3}\right)_{2} \quad(1,3$ and $10 \%$ weight related to the total silica content) were added under mechanical agitation to the sonosolution before gelation. Once the resulting gels had been left to age at room temperature, $\mathrm{H}_{2} \mathrm{~S}$ gas was diffused by thermal decomposition of thioacetamide (TAA). Small CdS crystals are then produced by precipitation inside the silica matrix.

The quantum confinement behaviour is manifested by the characteristic blue-shift in the UV-Vis spectrum (Fig. 16a left axis) in relation to the bulk optical absorption band of CdS with a bandgap energy of $2.53 \mathrm{eV}$ (490 nm wavelength). This behaviour is consistent with the Éfros-Éfros model [3] which gives the absorption threshold energy $\mathbf{E}$ dependent on the inverse square of particle mean radius $\mathbf{R}$ as follows:

$$
E=E_{g}+\frac{\hbar^{2} \pi^{2}}{2 \mu R^{2}}
$$

where $\mathbf{h}$ is the Planck constant, $\boldsymbol{\mu}$ is the electron effective reduced mass and $\mathbf{E}_{\mathbf{g}}$ is the bandgap energy for the bulk crystal. These energy values can be obtained from the position of the optical absorption band of the different samples. 
Fig. 16 also includes the photoluminescence (PL) yield (right axis) in which two bands can be observed. The higher-energy band is related to the intrinsic recombination mechanism. There may also be weak allowed transitions for dots with $\mathrm{R} \cong \mathrm{a}_{\mathrm{B}}=3.2 \mathrm{~nm}$ in $\mathrm{CdS}\left(\mathrm{a}_{\mathrm{B}}\right.$ being the bulk exciton Bohr radius), because kinetic energy terms are dominant over Coulomb effects, and this produces the observed line broadening. On the other hand, the lower-energy band is attributed to the recombination of trapped carriers. A red-shift of the PL emission relative to the absorption band can also be observed, which is crystal size-dependent: the red-shift increases as the particle size decreases. The origin of this effect seems to be in a distortion of the crystal lattice after the transformation of the $\mathrm{CdO}$ (cubic) into $\mathrm{CdS}$ (hexagonal) at $150^{\circ} \mathrm{C}$, which provokes compressive strains. This red-shift/distortion influences the intrinsic band due to the sulfur ion vacancies acting as potential hole traps. The observable differences in the PL spectra also inform about the crystal surface traps; the CdS3 sample seems to have lower trap states than the CdS1. However, the CdS10 sample shows an overlapping of the two bands indicating a significant distortion of the lattice. In the light of these size-dependent effects (blue- and red-shifts), the lack of correlation between crystal size and CdS content must be attributed to the slight difference of the silica network pore structure which affects diffusion of the $\mathrm{H}_{2} \mathrm{~S}$ gas.

The PL yields were measured by using the third harmonic (3.49 eV) of a pulsed Nd:YAG laser (6 ns pulse at $10 \mathrm{~Hz}$ repetition rate). Using a cylindrical lens, the laser beam is focused on the edge of the sample to form a narrow rectangular strip (50 $\mu \mathrm{m}$ to $2 \mathrm{~mm}$ long and $20 \mu \mathrm{m}$ wide) $[159,160]$. The amplified luminescence (AL) at right angles to the direction of the strip is measured for different strip lengths. In all cases the PL yield measurements were taken at atmospheric pressure in air at room temperature. Use of the variable strip length (VSL) method is reported in [161]; in this method the PL yield along the focus axis is related to the optical gain by the relationship: $\quad I_{A L}=\frac{I_{S P}}{g}\left(e^{g L}-1\right)$,

where $\mathrm{I}_{\mathrm{AL}}$ and $\mathrm{I}_{\mathrm{SP}}$ are the amplified and spontaneous emission, respectively. The net gain coefficient is $\mathbf{g}$ and $\mathbf{L}$ is the stripe length. The PL yield increases in a superlinear fashion for the intrinsic band, accounting for a net gain coefficient as can be seen in Fig. 17. The gain is spectrally broad with a steeper decrease on the high-energy side and a long tail stretching to lower energies; in all cases the optical gain reveals the stimulated emission from the CdS nanocrystals as QDs.

The TEM micrograph in Fig. 18 confirms the fine and homogeneous distribution of the CdS nanocrystals immersed in the porous silica matrix, with an average crystal size of $4.6 \mathrm{~nm}$, as indicated by their size distribution in the inset of Fig. 18 . 
The electronic and optical properties of IV-VI semiconductors such as PbS have also been topics for extensive research in the last three decades. Their narrow band-gap permits strongly quantum-confined excitons (electron-hole pairs) to be created when microcrystallites are smaller than the bulk exciton Bohr radius $\left(\mathrm{a}_{\mathrm{B}}=18 \mathrm{~nm}\right.$ for $\left.\mathrm{PbS}\right)[4,162,163]$. This is the case for $\mathrm{PbS}$ crystallites presenting a particle size smaller than $18 \mathrm{~nm}$, with a threshold of the optical absorption band at $0.41 \mathrm{eV}$ for the bulk material. Many approaches have been explored for the formation of small $\mathrm{PbS}$ nanocrystals and their incorporation into solid and transparent matrices [164, 165, 166], and one approach is to use the sol-gel process combined with colloidal chemistry $[167,168,169]$. This technique prevents agglomeration and allows control of the particle size and size distribution; although the small precipitates produced are unstable, surface-capping methods [170] may help to overcome this drawback.

Gel matrices and films have been used as hosts for semiconductor quantum dots since more than ten years ago, mainly because low temperatures are required to create the network. However, they present a high porosity which makes them especially active for humid condensation and oxidation, thus favouring subsequent crystal growth. In spite of these inconveniences, this topic arouses interest and recently several studies have been published [171, 172, 173, 174, 175] . Oxidation could be limited by sealing pores and thus reducing the specific surface area. One of the methods for achieving this is by using organic polymers in the gel formation; this allows mechanically-improved silica gel matrices to be synthesised via copolymerisation with silicon precursors, named ormosils. These OIHM present properties that make them especially attractive for optical applications [176,177].

Using this procedure $\mathrm{PbS}$ quantum dots stabilised with surface capping agents (SCA), incorporated into rigid transparent $\mathrm{SiO}_{2}$ sono-ormosils, have been successfully synthesized for nonlinear optical applications [iError! Marcador no definido.]. Table 6 gives the textural parameters evaluated from $\mathrm{N}_{2}$ isotherms. A decrease in the specific surface area with an increase in the PbS content is observed. This behaviour could be due to differences in pore sizes as a consequence of the steric effects derived from the non-bonded 3-mercaptopropyl groups, since they are electrostatically opposed to the silica network. This assumption is confirmed by the good agreement existing between the apparent densities calculated from the porous volume and from the geometrical dimensions. Bulk densities $\left(\rho_{s}\right)$, were calculated taking into account the corresponding percentages by weight in the composite $\left(\mathrm{SiO}_{2}\right)_{1-\mathrm{x}}-(\mathrm{PbS})_{\mathrm{x}}$, by using $2.2 \mathrm{~g} \cdot \mathrm{cm}^{-3}$ for vitreous silica and $7.5 \mathrm{~g} \cdot \mathrm{cm}^{-3}$ for $\mathrm{PbS}$. Finally, the average pore size values in the last column corroborate the fine porosity of the host silica matrix.

An HRTEM micrograph from $\mathrm{PbS} / \mathrm{SiO}_{2}$ sample is shown as Fig. 19a. Spherical and/or cubic morphology of particles, and lattice planes in some cases, can be clearly seen. A mean diameter of 
around $10.5 \mathrm{~nm}$ with a standard deviation of $1.2 \mathrm{~nm}$ was obtained from the distribution plotted in Fig. 19b. In such a situation, the SCA molecules passivate the $\mathrm{Pb}$ surface sites on the subcritical $\mathrm{PbS}$ crystals and prevent their oxidation. Surplus uncoordinated S sites act as potential surface traps which produce important steric effects on the fine silica network. The final size of the PbS particle is then controlled by adjusting the relative concentrations of SCA and sulphide [166,178]. Moreover, the ormosil matrix surrounding the $\mathrm{PbS}$ crystals prevents their subsequent growth and oxidation.

In the structural analysis an additional measurement was made by means of Small Angle Neutron Scattering (SANS), at room temperature, using a neutron wavelength of $6.02 \AA$, at the Berlin Neutron Scattering Center (HMI) in Berlin. The corrected SANS intensity curves are shown in Fig. 20 [179, 180]. In all cases, two regions can be discerned, separated by the well-defined crossover point around $\mathrm{q}=0.1 \mathrm{~nm}-1$. For high q-values a wide plateau is apparent, which is characteristic of fine well-shaped scatters homogeneously distributed, typical of a material with fine porosity. In contrast, the increased signal at low q-values is characteristic of larger polydisperse particles, as could be produced by the polymer cross-links or/and the $\mathrm{PbS}$ nanocrystals $(6.5 \mathrm{~nm}$ size). The scattering from the undoped matrix is also included, inset of Fig. 20. In the absence of crystals, a smooth broad peak develops at $\mathrm{q}=0.5 \mathrm{~nm}^{-}{ }^{1}$, which accounts for the short-range order of the homogeneous pore distribution.

It is well-known that crystals in gels grow by a diffusion-controlled process. In such a situation, the concentration gradient around the crystal depletes a surrounding volume larger than the crystal in which no other crystals are present [181]. In accordance with this understanding, the experimental intensities were fitted by the two-correlation model proposed by Debye and Bueche $[182,183]$ where the scattering cross-section behaves as:

$$
\frac{d \Sigma}{d \Omega}(q)=\frac{A_{1}}{\left(1+q^{2} a_{1}^{2}\right)^{2}}+A_{2} \exp \left(-\frac{q^{2} a_{2}^{2}}{4}\right)
$$

where the correlation lengths $\mathrm{a}_{1}$ and $\mathrm{a}_{2}$ represent the medium-range and short-range fluctuations of the scattering length density, respectively. The parameters $A_{1}$ and $A_{2}$ are related to the corresponding volume fraction of each phase. Eq.(1) can be considered as the form factor P(q) of the heterogeneities, then the total scattering cross-section becomes $I(q)=\Phi \cdot P(q) \cdot S(q)$, $\Phi$ and $S(q)$ being the particle number density and the structure factor, respectively. The structure factor $S(q)$ was evaluated assuming the Percus-Yevick hard-sphere model, and using the expression of Ashcroft and Lekner [184]. This interpretation of the SANS patterns indicates the existence of a depleted region around each $\mathrm{PbS}$ crystal, where the growth of another crystal is inhibited [181]. 
The structure factor accounts for the interparticle interference terms which could be produced either by crystals or pores. The results of such a fitting are shown in Table $\mathbf{7}$ and the fitted curves from I(q) are drawn in Fig. 20. The undoped matrix does not fit (inset Fig. 20) this twofold correlated structure, as can be deduced from the noisy signal at low-q. Thus the observed increase of intensity must be due to the local heterogeneities produced by the polymer cross-links between chains [185] with the silica network at the boundary of the SCA molecules surrounding the PbS nanocrystals. From Table 7, it can be stated that the crossover point at $\mathrm{q}=0.1 \mathrm{~nm}^{-1}$ resolves the twofold structure for the doped samples. Thus, $\mathrm{A}_{1}$ and $\mathrm{a}_{1}$ grow with the $\mathrm{PbS}$ content. These values are surprisingly high compared with those of $\mathrm{A}_{2}$ and $\mathrm{a}_{2}$, in spite of the higher scattering length density of the matrix/pores (short-range) relative to that of the PbS/matrix (medium-range). These results indicate a dot density higher than those for QDs in Schott filters [181] due to the smaller depleted region. We attribute the underestimation of $\mathrm{a}_{2}$ values with regard to the pore size calculated from physisorption (see Table 6), to the incoherent scattering contribution for $\mathrm{q}>1 \mathrm{~nm}^{-1}$, in the absence of which the "knee" of the fitted curves at $\mathrm{q}=2 \mathrm{~nm}^{-1}$ would shift to lower values, thus indicating larger pores.

These results are promising to obtain strong quantum confinement $\left(\mathrm{R}<\mathrm{a}_{\mathrm{B}}\right)$ of the $\mathrm{PbS}$ quantum dots from which large non-linear optical behavior may be expected.

\subsection{Hybrid organic/inorganic sonogels.}

Organic modified silicates (ORMOSIL) can be obtained by supercritical drying in ethanol of the corresponding alcogel, producing a hybrid organic/inorganic aerogel. The new material obtained takes advantage of the properties of organic polymers, including flexibility, low density, toughness and formability, whereas the inorganic component contributes properties such as surface hardness, modulus strength, transparency and high refractive index.

These hybrid aerogels can be classified as Type C Ormosils, according to the Mackenzie classification; that is, the organic and the inorganic parts are chemically bonded, via covalent or iono-covalent bonds. The stronger nature of the covalent bond gives considerable improvement of the mechanical properties of the composites. One of the best methods for obtaining organicinorganic hybrid materials (OIHM) by this approach is the combined reaction of a silanolterminated polymer (PDMS), as the organic component, with a silicon alkoxide (namely, TEOS or TMOS) as the inorganic component. In the silanol-terminated polymers, the non-bridging oxygen $\mathrm{Si}-\mathrm{CH}_{3}$ groups are dominant, depending on the average polymer molecular weight. The end chain groups $-\mathrm{OH}$ or $-\mathrm{OR}$ radicals link the polymer with the silica network via the copolymerisation between PDMS and TEOS, as stated in paragraph 3.1.1. 
Type $\mathrm{C}$ ormosils comprising TEOS and PDMS can be also promoted by high power ultrasound, when they are known as "sono-ormosils"; these are denser and have enhanced mechanical properties. As a comparison, in Table 8, the Vickers hardness value of some representative materials is shown for comparison with this new sono-ormosil. This new material falls between the softest glasses and the hardest transparent plastics. With higher PDMS content the ormosil behaves as a more rubbery material.

This proposed route for obtaining these materials incorporates an organic phase in the inorganic precursor sol, in combination with the assistance of high-power ultrasound [65, 186, 187 , 188]. Given that in the sol-gel process little or no heating is required, organic molecules with low thermal stability can be incorporated into an inorganic ceramic or glassy host. Thus the "sonogel" route is another approach to modification of the sol-gel process. Ormosils can also be excellent matrices for non-linear optical materials due to their high transparency, inertness, mechanical strength and ease of preparation [189]. Similarly semiconductor quantum dots have been dispersed in ormosils [;Error! Marcador no definido.] and dye lasers are enhanced [190].

A new route is now being exploited in this field of OIHMs. The process consists of drying the wet sono-ormosil at the supercritical conditions of pressure and temperature of the added liquid, to obtain a sono-ormosil aerogel, also known as an aer-ormosil. Aerogels have been successfully obtained from a TEOS/PDMS sono-ormosil. Results seem to confirm the hybrid characteristics of these aerogels; that is, the organic groups are retained in the sample that can still be considered as an OIHM. We have studied the pyrolysis process in producing these aerogels from sonogels (550 J $\mathrm{cm}^{-3}$ ); Fig. 21 shows the DTG results for the sample aerogel in air and in inert atmospheres. As can be seen, the organics decompose at $230^{\circ} \mathrm{C}$ (DTG in air), and then there is a further gradual weight loss between $500-600^{\circ} \mathrm{C}$, explained by the remaining hydroxyl groups producing water as byproduct. In contrast, the pyrolysis under an inert atmosphere (DTG in inert gas) shows a different behaviour; up to $400^{\circ} \mathrm{C}$ the aerogel is thermally stable, and between $400-600^{\circ} \mathrm{C}$ carbonisation produces a redistribution between $\mathrm{Si}-\mathrm{O}$ and $\mathrm{Si}-\mathrm{C}$ bonds, but no destruction of the organics groups, as reported by Zang and Pantano [191]. The transition to an inorganic material occurs between 700$800^{\circ} \mathrm{C}$, with decomposition of the methyl groups. Above $1000^{\circ} \mathrm{C}$ Babonneau et al. [192] report, from ${ }^{29} \mathrm{Si}$ MAS-NMR experiments, the presence of an oxycarbide phase and free carbon in a DMDES/TEOS ormosil.

These new solids also present variation in several physical properties; as an example, the methyl group on the polymer chain makes these aerogels hydrophobic as is apparent from the photograph of Fig. 22, from which a contact angle greater than $120^{\circ}$ can be estimated. 


\subsubsection{Mechanical behaviour.}

Mechanical test were performed in an AG-I Autograph from Shimadzu. For the experiments an uniaxial compression device was used, equipped with a load cell of $5 \mathrm{kN}$. In all the experiments the strain rate was fixed at $0.5 \mathrm{~mm} / \mathrm{s}$ at room temperature. For this mechanical test samples were cast as cylinders of $20 \mathrm{~mm}$ length and $10 \mathrm{~mm}$ diameter.

The results of the stress-strain experiments are shown in Fig. 23; the incorporation of organic polymer chains into the inorganic structure of silica gel dramatically changes the mechanical behaviour. First, the PDMS aerogel (PDMS $40 \%$ by wt.: bottom curve) presents an elastomeric behaviour indicating a softer solid network than that of the pure silica gel (top curve); in other words, the polymeric chains are acting as springs. As the stress increases, the PDMS aerogel begins to deform less and less, indicating that the solid network is becoming stiffer; then the action of the polymer stops (at $25 \%$ strain) and the inorganic silica network begins to act, and ends with a similar slope (elastic modulus) as the pure silica aerogel (top curve). The upward curvature indicates a continuous increase in its elastic modulus, which is characteristic of elastomers that loose their stiffness as the polymer chains deform. First the polymer chain deforms like a spring by reducing the $\mathrm{Si}-\mathrm{O}-\mathrm{Si}$ bond angle, giving large strain with low stress. In a second state, the chain penetrates into the micropores of the inorganic silica nodules behaving like a dashpot to dampen the small strains induced as the stress increases, and finally the failure of the network provokes the fracture. Thus the solid presents first an elastic behaviour and then, in a second step, becomes like a viscous liquid, giving a total mechanical behaviour of a visco-elastic solid. A similar elastomer signature can be observed in the other samples as the polymer content is increased. The experimental values from the stress-strain curves are given in the Table 9.

As can be seen, this polymeric aerogel exhibits a complex behaviour on deformation, flowing like a liquid or responding elastically like a solid, depending on the time scale of the dynamics of the molecules. This mechanical duality is called visco-elasticity $[193,194]$ and can be characterized by the relaxation modulus, the stress time evolution at fixed strain. Such relaxation behaviour is illustrated in the inset of Fig. 23 for a TEOS/PDMS aerogel (PDMS $40 \%$ by wt); under small deformation $(\varepsilon=15 \%)$, a biexponential decay reveals two mechanisms in the relaxation process: a fast mechanism corresponding to the elastic polymer chains (like springs) and another slow mechanism due to the stiff porous silica matrix (like a dashpot).

The technique known as nanoindentation enables the mechanics of nanomaterials to be probed [195] and permits direct measurements of physical property of heterogeneous materials with close spatial resolution. This technique has traditionally been used to characterize elasto-plastic hard materials, although many groups have used the technique on soft tissues, such as demineralized dentin [196] and vascular tissues [197]. The problem of suitable analytical 
techniques comes from the influence of interfacial adhesive forces, which can affect the indentation contact area and has not been validated for very soft materials, with an elastic modulus below 5 $\mathrm{MPa}$. Some authors have demonstrated the validity of nanoindentation in measuring the elastic modulus of pure PDMS with different degrees of crosslinking [198].

In this context several studies have concentrated on the sol-gel method and specifically on aerogels [199]. This technique seems to be very useful for the study of such complex structures as hybrid organic/inorganic aerogels, which are composed of an inorganic phase covalently bonded to an organic polymer chain.

In a standard load-depth curve, the initial slope on the unloading branch (stiffness-S) is related to the reduced elastic modulus $\left(\mathrm{E}_{\mathrm{r}}\right)$ by the following relationship:

$$
\mathbf{S}=\left(\frac{\mathbf{d P}}{\mathbf{d h}}\right)_{\max }=\frac{2}{\sqrt{\pi}} \mathbf{E}_{\mathrm{r}} \sqrt{\mathbf{A}}
$$

in which $\mathrm{A}$ is the area of the imprint on the sample, in this case a Berkovich pyramidal tip $\left(A=24.5 h^{2}\right.$, $h$ being the depth). The slope $S$ is calculated after least square fitting by the power law function proposed by Oliver and Pharr [200,201] in the form: $\mathbf{P}=\boldsymbol{\alpha h}^{\mathbf{m}}$, where $\boldsymbol{\alpha}$ contains geometric constants, the elastic modulus of both sample and indenter, and Poisson's ratio, and $\mathbf{m}$ is the power law exponent related to the geometry of the indenter (for a cone $\mathbf{m}=2$ ). The hardness is calculated simply by $\mathbf{H}=\mathbf{P} / \mathbf{A}$ and the elastic recovery parameter as $\mathbf{E R P}=\frac{\mathbf{h}_{\max }-\mathbf{h}_{\mathbf{f}}}{\mathbf{h}_{\max }}, \mathbf{h}_{\mathbf{f}}$ being the nonrecovered depth of the indenter inside the aerogel sample.

Fig. 24 shows a typical load-depth hysteresis curve, in which the dramatic difference between the two samples (pure silica and PDMS hybrid aerogel) is apparent; as a first indication, the load necessary to provoke a displacement of $1 \mu \mathrm{m}$ is $33 \%$ greater for the pure silica sample compared with the hybrid aerogel with a polymer content of $10 \%$ by wt. Thus the influence of the polymer chains is mainly on the stiffness of the silica; there is a decrease in the hardness from 226 $\mathrm{MPa}$ for the pure silica to $24 \mathrm{MPa}$ for the hybrid aerogel sample, and consequently a better elastic recovery indicated by a greater depth interval $\left(\mathbf{h}_{\mathbf{f}}, \mathbf{h}_{\max }\right)$.

The inset of Fig. 24 shows a plot of the Young's modulus versus polymer content. The macroscopic Young's modulus from uniaxial compression (solid rhombus) is also included; this value comes close to that of the softer sites indicating that the polymer phase controls the mechanical behaviour at the macroscopic level. The silica clusters, bonded by the spring-like elastomeric polymer chains, act like a dashpot to give the final elastic modulus of a soft material.

Grid maps were recorded of 10X10 indentations, each $20 \mu \mathrm{m}$ apart. The total load-depth curves show a fan feature indicating stiffest sites against softest ones. The former are dominated by the inorganic silica clusters and the latter by the organic polymer. This picture is apparent in the 
map of the elastic recovery parameter depicted in Fig. 25a, in which elastic sites (white) correspond to those with low reduced modulus, and plastic sites (black) correspond to the hard regions of the aerogel.

In order to study the mechanical properties of these organic-inorganic aerogels in greater depth, we have performed creep tests on hybrid aerogels, as the time dependence of the strain at fixed stress [202]. Assays of this type have been used widely on different kinds of materials and, more specifically, on polymers [203]. From these tests the creep curve shows an instantaneous elastic deformation followed by a transitory state of retarded deformation, known as primary creep. During this period, the material can be understood to be undergoing a reinforcement process by deformation [204]. Then, the system reaches the stage of secondary creep, a steady state where equilibrium is found within the different mechanisms of strain and recovery. Creep curves from pure silica and hybrid PDMS aerogels are shown in Fig. 25b. They depict the typical saturation shape with an instant deformation, and then the primary regime of retarded strain and secondary creep of steady-state linear regime. It can be seen that the depth of the retarded strain is much greater in the hybrid than in the pure silica aerogel.

\subsubsection{Structural aspects.}

SANS measurements were carried out at room temperature on the V4 workstation at the Berlin Neutron Scattering Center of the HMI (Berlin). A neutron wavelength of $0.602 \mathrm{~nm}$, at three sample-detector distances 1,4 and $16 \mathrm{~m}$, was used to cover a $q$-range from 0.036 to $3.6 \mathrm{~nm}^{-1}$. Data were corrected using the software package available at HMI [205].

Fig. 26 shows the SANS experimental intensities of hybrid aerogels with different polymer content. Several features can be discerned; first, an increase of the intensity is apparent towards the low q-side. Then wide plateaus appear with Guinier radii ranging from 5 to $8 \mathrm{~nm}$ as the polymer content is increased from 10 to $50 \%$ by wt, as displayed in the inset of Fig. 26. The plateaus are followed by power law decay, with a slope getting steeper in line with the polymer content, up to a maximum value of -2.5 . The final parts of the curves are dominated by the incoherent scattering due to the ${ }^{1} \mathrm{H}$ atoms of the organic polymer in the methyl radicals.

In Fig. 26 a first shoulder at low-q $\left(0.04 \mathrm{~nm}^{-1}\right)$ is produced by the long range characteristic length governed by the "frozen-in" elastic constraints, which act through topologically-connected polymer cross-links. A shorter range correlation length at $\mathrm{q}=0.3 \mathrm{~nm}^{-1}$ in the plateau corresponds to the size of the so called "blobs", which can be considered to be composed of a nucleus of the silica cluster surrounded by the polymer distributed as a random coil (RC); the average size of the "blob" can be identified with the Guinier radius. This supposition is supported by the agreement between the results of non-linear fitting of the experimental curves and a mixed Gaussian random coil form 
factor (continuous line in Fig. 26) [206,207]. The wide Guinier region indicates the homogeneous distribution of these "blobs" as scatterers. As the polymer content is increased, the "blobs" grow as a consequence of the entanglement of the polymer chains.

The aggregates of the entangled polymer chains surrounding the silica clusters, the "blobs", form mass fractal units, their dimension $\mathrm{D}=2.5$ being characteristic of a cross-linked random coil structure. Although the aggregate does not strictly fulfil the conditions of self-similarity on different length scales to be considered a fractal object, it can be viewed as an object that does not fill the space totally. Moreover, this result suggests a kinetic growth mechanism based on the diffusion limited aggregation (DLA) of the monomer-cluster that has a fractal dimension of 2.5.

\subsection{Silica aerogel nanocomposites.}

Finally we present here some applications of the nanostructured sonogels described, in which a second component added in the liquid will act as the active phase.

\subsubsection{Bioactivity}

Hybrid organic/inorganic materials (OIHMs) are being used for implants since they are tolerated by the human organism, which creates a fibrous tissue when they are embedded in the body. However, they do not become bonded to the bone unless they are bioactive. In such case, a layer of hydroxycarbonate of apatite (HCA) grows and wraps around the material when it is immersed in blood plasma. An HCA layer is also formed when bioactive materials are soaked in solutions mimicking the features of plasma. To perform fully as an implant, these materials need to present mechanical behaviour very similar to that of human bone.

Recently, several mixtures obtained by ultrasonic agitation of colloidal silica with a sol solution containing tetraethoxysilane (TEOS) have been used to form crack-free monoliths. We have used the combination of colloid-polymer as precursor of the inorganic part of the OIHM with the aim of tailoring the porosity to control the density and mechanical strength in the range of those of human bone. Finally, in vitro bioactivity of this material has been promoted by adding colloidal silica particles to the initial sol. In ormosils, it has been shown that $\mathrm{Ca}^{++}$cations, together with unreacted silanols, form the bioactive hydroxyapatite layer in a simulated body fluid [208].

In general terms, those materials coated with a layer of amorphous calcium phosphate that crystallises into HCA after being soaked in SBF (Simulated Body Fluid) are categorized as bioactive. The biologically active HCA layer facilitates interaction between the material and biological entities, and it has been proposed as a first phase in the sequence of reactions that result in the creation of a mechanically strong bond between the bioactive materials and the living tissues [209]. To confirm the formation of calcium phosphate on the hybrids after the in vitro assays, the 
variations in their surfaces with the time of soaking in SBF were also studied by SEM and EDX. Fig. 27 presents the SEM images and the corresponding EDX spectra of an aerogel composite after 0, 1, 3 and 7 days of immersion in SBF. After 1 day, the SEM micrograph shows no significant differences with respect to the initial sample $(\mathrm{t}=0)$. However, after 3 days in SBF, the surface appears cracked, with deep channels forming. After 7 days, some kind of material appears to have formed inside the channels. The corresponding EDX spectra show that the proportion of $\mathrm{Ca}$ and $\mathrm{P}$ on the material surface increases slowly during the first 3 days of assay, up to 0.14 mol- $\%$ for the two elements. However, the EDX spectrum of the sample immersed for 7 days shows the presence of significant amounts of $\mathrm{P}(0.75 \mathrm{~mol}-\%)$ and $\mathrm{Ca}(1.4 \mathrm{~mol}-\%)$. This result demonstrates the formation of calcium phosphate on the surface of the hybrid [154,155].

In another approach using synthetic wollastonite powders as the active phase and modifying the inorganic TEOS gel matrix with MTES (methyl triethoxysilane), the bioactive behaviour was improved. The formation of a layer of HA crystals on the aerogel surface is apparent in the micrograph of Fig. 28; roughly spherical shaped particles, formed by fine lamellar crystals, can be seen. A quantitative yield analysis on the EDX spectrum indicates a $\mathrm{Ca} / \mathrm{P}$ ratio of 1.7 , almost the same composition as that of the HA.

\subsection{2. $\mathrm{CO}_{2}$ sequestration}

Among the gases contributing to the "green house effect", the influence of $\mathrm{CO}_{2}$ has been estimated at $40-50 \%$ of the total. Currently, the policy proposed for dealing with this problem is the reduction of gas emissions from power generation processes, transport and especiallycontaminating industries (such as cement factories). Any viable strategy with this objective requires technologies that incorporate $\mathrm{CO}_{2}$ elimination processes, i.e., separation, capture (sequestration), disposal or storage and, finally, elimination. Everything must be carried out at costs that are feasible for the gas-emitting industries, organisations and countries to bear.

It is known that some natural silicates form carbonate when in contact with $\mathrm{CO}_{2}$. In particular, wollastonite $\left(\mathrm{CaSiO}_{3}\right)$ reacts to produce calcite and silica. This is a natural reaction that has operated over millions of years to reduce the $\mathrm{CO}_{2}$ in the Earth's atmosphere. Wu et al. (2001) [210] and Tai et al. (2006) [211] have published results on the rate of conversion of wollastonite $\left(\mathrm{CaSiO}_{3}\right)$ into calcite $\left(\mathrm{CaCO}_{3}\right)$ for different experimental protocols. These values must be interpreted to determine the efficiency of $\mathrm{CO}_{2}$ fixation by the minerals. Thus, starting from a powdered wollastonite sample in a reactor at atmospheric pressure and room temperature, $\mathrm{Wu}$ et al. obtained a conversion rate of $14 \%$ of wollastonite into calcite after 22 days. Later, a comparative study has been carried out [212] analysing different types of sample and experimental conditions, and has given more encouraging results. In Fig. 29 the carbonation reaction is illustrated by the X-Ray 
diffraction peak and by the SEM micrograph. In this case, the wollastonite is almost entirely dissolved and the calcite peak can be observed standing out from the other peaks. The reaction efficiency can be estimated as relatively high: their analysis reveals that almost $85 \%$ of the wollastonite is dissolved. The SEM micrograph shows the by-products of the aerogel composite after exposure to $30 \mathrm{~min}$ of $\mathrm{CO}_{2}$ flow, where the individual monocrystals (rhombohedric-like) of carbonates together with unreacted silica gel can be observed. These results indicate advantages in terms of fast reaction time and efficiency, which should open up new uses for composites of this type $[156,157]$.

\section{ACKNOWLEDGEMENTS}

The authors thank to the Spanish Ministry of Science and Technology for financial support under project MAT2005-1583. The authors are members of the PAI TEP-115 Research Group of the Junta de Andalucía (Spain).

\section{Appendix I. Index of acronyms.}

BET Brunauer-Emmet-Teller (specific surface area method)

BJH Barret-Joyner-Halenda (PSD method)

CERAMER CERAmic and polyMER

CM Cluster Model

CRN Continuous Random Network

DCCA Drying Control Chemical Additive

DLA Diffusion-Limited Aggregation

DMDES Dimethyl diethoxysilane

DMS Dimethyl siloxane

DPS Diphenyl siloxane

DSC Differential Scanning Calorimetry

DTA Differential Thermal Analysis

EDTA Ethylene diamine tetra-acetic acid

EDX Energy Dispersive X-ray Spectroscopy

EtOH Ethanol 
HA Hydroxyapatite

HCA Hydroxycarbonate apatite

HK Horvath-Kawazoe (PSD method)

HPC Hydroxypropyl cellulose

IPA isopropyl alcohol.

iPrOH isopropanol

MAS NMR Magic Angle Spinning Nuclear Magnetic Resonance

MEM Maximum Entropy Method

$\mathrm{MeOH}$ Methanol

MPTMS 3-Mercaptopropyl-trimethoxysilane

MTES Methyl-triethoxylsilane

MTMS Methyl-trimethylsilane

NBO Non-Bridging Oxygens

NLO Non-Linear Optics

NMR Nuclear Magnetic Resonance $\left({ }^{1} \mathrm{H},{ }^{29} \mathrm{Si},{ }^{13} \mathrm{C},{ }^{17} \mathrm{O}\right.$ for different isotopes $)$

OIHM Organic-Inorganic Hybrid Materials

ORMOCER ORganic MOdified CERamic

ORMOSIL ORganic MOdified SILicate

PC Polycarbonate

PDMS Polydimethyl siloxane

PDPS Polydiphenyl siloxane

PEG Poly ethyleneglycol

PEO Poly ethyleneoxide

PhTES Phenyl triethoxysilane

PET Polyethylene terphtalate

PMMA Polymethyl metacrylate

PPO Polyoxopropylene

PSD Particle Size Distribution

PTMO Polytetramethylene oxide

PVA Polyvinyl alcohol

QDs Quantum Dots

RCP Random Close Packing

RDF Radial Distribution Function

RLA Reaction-Limited Aggregation

SANS Small-Angle Neutron Scattering 
SAXS Small-Angle X-ray Scattering

SBF Simulated Body Fluid

SCA Surface Capping Agent

SEM Scanning Electron Microscopy

TAA Thioacetamide

TEM Transmission Electron Microscopy

TEOS Tetraethyl ortosilicate

TGA Thermogravimetric Analysis

TIPT Tetraisopropyltitanate

TMOS Tetramethyl ortosilicate

TMS Tetramethylsilane

TMSPM Trimethoxysilylpropylmethacrylate

WAXS Wide-Angle X-ray Scattering

XRD X-Ray Difracction

\section{Appendix II. Commonly used terms}

- Solution: Homogenous liquid in a single phase

- Sol: Homogenous liquid containing a fine colloidal dispersion of solid particles whose size is below that of gravitational influence. Their stability is due to electrostatic and steric effects.

- Gel: coherent solid structure immersed in a fluid (water-aquagel; alcohol-alcogel)

- Precipitate: Solid particles without connection and under gravitational influence

- Xerogel: Dry solid phase of the gel obtained by evaporation of the interstitial liquid. Polymerization, syneresis and coarsening collapses the xerogel microstructure.

- Aerogel: Dry solid phase of the gel obtained by venting off the liquid in supercritical conditions. It retains the microstructure of the original gel.

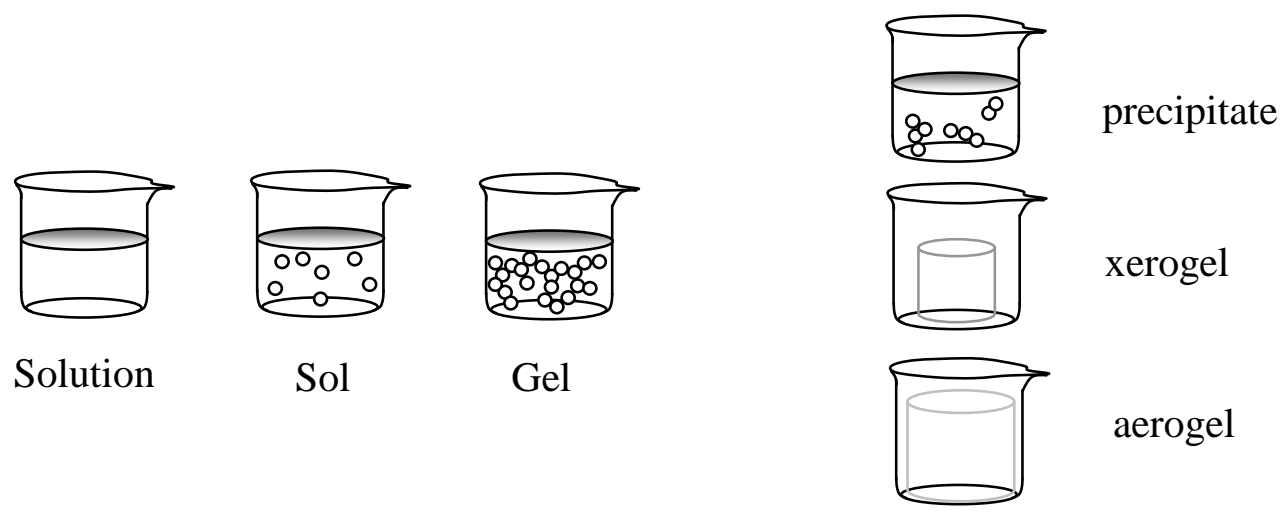




\section{REFERENCES}

1 E.O. Hall, Proc. Phys. Soc. London, Sect B 64, 747 (1951).

2 N.J. Petch, J. Iron Steel Inst. 174, 25 (1953).

3 L. Efros and A. Efros, Sov. Phys. Semicond. 16, 772 (1982).

4 U. Woggon in “Optical Properties of Semiconductors Quantum Dots”, Springer Tracts Modern Physics (vol.136). (Springer, Berlin, 1997).

5 J.B. Lambert in "Traces of the Past: Unraveling the secrets of archeology through chemistry". Addison-Wesley Helix Books, (1997) p. 319.

6 M.C. Rocco, J. Nanoparticle Res., 1, 1 (1999).

7 MRS Bulletin, “Mechanical behaviour of Nanostructured Materials”, 24(2) (1999).

8J.J. Von Ebelmen, Compt. Rend. Acad. Sci. 19, 398 (1844)

9 T. Graham, J. Chem. Soc., 17, 318 (1864).

10 T.E. Word and H. Dislich in "Sol-Gel Science and Technology", Ed. E. Pope, S. Saka, L. Klein, (Ceramics Transactions Vol 55), Am. Cer. Soc., Ohio USA (1995) p. 3

11 R. Roy and E.F. Osborn, Am. Mineral. 39, 853 (1954).

12 R. Roy and E.F. Osborn, Trans. Brit. Ceram. Soc., 53, 525 (1954).

13 C.T. Hardy in "Sol-Gel Processes For Ceramic Nuclear Fuels" (IAEA, Austria, 1968) p.33.

14 H. Dislich, Angewandte Chemie, International Edition, 10(6), 363 (1971)

15 "Sol-gel technology for thin films, fibers, preforms, electronics and specialty shapes" Ed. L. Klein, Noyes publications, New Jersey, (1988).

16 R. Roy, J. Am. Ceram. Soc. 52, 344 (1969)

17 H. Schroeder, Phys. Thin Films 5, 87 (1967).

18 D. R. Secrist, and J.D. Mackenzie, Modern Aspect Vitreous State 3, 149 (1964)

19 International Workshop on "Glasses and Ceramics from Gels"

$1^{\text {st }}$ Ed. V. Gotardi, J. Non-Cryst. Solids 48 (1982)

$2^{\text {nd }}$ Ed. H. Scholze, J. Non-Cryst. Solids 63 (1984)

$3^{\text {rd }}$ Ed. J. Zarzycki, J. Non-Cryst. Solids 82 (1986)

$4^{\text {th }}$ Ed. S. Sakka, J. Non-Cryst. Solids 100 (1988) 
$5^{\text {th }}$ Ed. M. Aegerter, J. Non-Cryst. Solids 121 (1990)

$6^{\text {th }}$ Ed. L. Esquivias, J. Non-Cryst. Solids 147\&148 (1992)

$7^{\text {th }}$ Ed. K. Kamiya and J. Livage, J. Sol-Gel Sci. and Tech. 2 (1994)

$8^{\text {th }}$ Ed. R. Almeida and L. Ilharco, J. Sol-Gel Sci. and Tech. 8 (1997)

$9^{\text {th }}$ Ed. R. Hand, P.F. James and A. Seddon, J. Sol-Gel Sci. and Tech. 13 (1998)

$10^{\text {th }}$ Ed. M. Yamane, J. Sol-Gel Sci.and Tech. 19 (2000)

$11^{\text {th }}$ Ed. M. Guglielmi, J. Sol-Gel Sci. and Tech. 26 (2003)

$12^{\text {th }}$ Ed. J. Bartlett, J. Sol-Gel Sci. and Tech. 30 (2004)

$13^{\text {th }}$ Ed. F. Babonneau and M. Aegerter, J. Sol-Gel Sci. and Tech. 40 (2006)

20 J. Brinker and G. Scherer, Sol-Gel Science: the Physics and Chemistry of Sol-Gel Processing, Academic Press, San Diego, CA (1990)

21 J T Davis and E.K. Rideal, Interfacial Phenomena, Academic Press, New York (1963)

22 P.J. Flory, Faraday Disc. Chem. Soc. 57, 7 (1974)

23 E M Rabinovich, in Sol-gel Technology for Thin Films, Fibers, Preforms, Electronics and Special Shapes ed. L.C. Klein, Noyes, Park Ridge, N.J. (1988), p. 260

24 A. Van Blaaderen, J. Van Geest and A. Vrij, J. Colloidal and Interface Sci. 154, 481 (1992)

25 R. Iler, The Chemistry of Silica, Wiley, New York, (1979)

26 S.S. Kistler, Nature, 127, 741 (1931).

27 S.S. Kistler, J. Phys. Chem., 34, 52 (1932).

28 S.J. Teichner, G.A. Nicolaon, M.A. Vicarini and G.E.E. Gardes, Adv. in Coll. and Interf. 5, 245 (1976).

29 J. Phalippou, M. Prassas and J. Zarzycki, J. Non-Cryst. Solids 48, 17 (1982).

30.ISA1- J. Fricke, Aerogels, Springer Proc. Phys. 6, Springer Verlag, Heidelberg (1986).

ISA2- R. Vacher, J. Phallipou, J. Pelous, and T. Woignier, Proceedings of the 2nd

International Symposium on Aerogels, Journal de Physique, Colloque C4 (1989).

ISA3- J. Fricke, Proceedings of the 3rd International Symposium on Aerogels, J. Non-Cryst.Solids 145 (1992).

ISA4- R.W. Pekala and L.W. Hrubesh, Proceedings of the 4th International Symposium on Aerogels, J. Non-Cryst. Solids 186 (1995).

ISA5- R. Vacher, J. Phallipou ISA-5 International Symposium on Aerogels N5, J. Non-Cryst.

Solids 225 (1998)

ISA7- Proceedings of the 7th International Symposium on Aerogels, Journal of Non-Crystalline Solids 350 (2005)

31 D. Levy, X. Quintana, C. Rodrigo and J.M. Oton, in Sol-Gel Optics-III, SPIE Proc., Ed. by J.D. Mackenzie, San Diego, CA, (1994) vol. 2288, p. 529. 
32 B.D. MacCraith, in Sol-Gel Optics-III, SPIE Proc., Ed. by J.D. Mackenzie, San Diego, CA, (1994) vol. 2288, p. .

33 J. Livage, J.M. DaCosta and I. Desportes, in Sol-Gel Optics-III, SPIE Proc., Ed. by J.D. Mackenzie, San Diego, CA, (1994) vol. 2288, p. .

34 Y.H. Xu, CH. Cheng and J.D. Mackenzie, J. Non-Cryst. Solids 176, 1 (1994).

35 CH. Cheng, Y.H. Xu and J.D. Mackenzie, Ferroelectrics 152, 31 (1994).

36 H. Schmidt, J. Non-Cryst. Solids 73, 681 (1985)

37 J.D. Mackenzie, Q. Huang and T. Iwamoto, J. Sol-Gel Sci. and Tech., 7,151 (1996)

38 J.D. Mackenzie, J. Sol-Gel Sci. and Tech. 26, 23 (2003).

39 S.J. Kramer, F. Rubio-Alonso and J.D. Mackenzie, in "Better Ceramics through Chemistry VII: Organic-Inorganic Hybrid Materials”, Eds. by B.K. Coltrain, C. Sanchez, D.W. Schaefer and G.L. Wilkes, MRS, Pittsburgh (1996) p. 295.

40 S. Amberg-Schwab, M. Hoffmann, H. Bader and M. Gessler, J. Sol-Gel Sci. and Tech. 13, 141 (1998).

41 C. Sánchez, G.J.de A.A. Soler-Illia, F. Ribot, T. Lalot, C.R. Mayer and V. Cabuil, Chem. Mater. 13,3061 (2001)

42 P. Gómez-Romero and C. Sánchez, "Functional Hybrid Materials”, Willey-VCH, Germany, (2004).

43 K.S. Suslick and G.J. Price, Annu. Rev. Mater. Sci. 29, 295 (1999).

44 K.S. Suslick, Science 247, 1439 (1990).

45 Lord Rayleigh, Phil. Mag. 34, 94 (1917).

46 T.G. Leighton, in "The Acoustic Bubble”, London Academic (1994).

47 E.B. Flint and K.S. Suslick, Science 253, 1397 (1991).

48 K.S. Suslick, Y. Didenko, M.M. Fang, T. Hyeon, K.J. Kolbeck, W.B. McNamara III, M.M. Mdleleni and M. Wong, Phil. Trans. R. Soc. Lond. A 357, 335 (1999).

49 S.J. Doktycz and K.S. Suslick, Science 247, 1067 (1990).

50 H. Frenzel and H. Schultes, Z. Phys. Chem. 27b, 421 (1934).

51 K.S. Suslick and L.A. Crom, Handbook on Acoustics (ed. M. Crocker), Wiley-Intescience, NY, (1998) p. 243.

52 W.B. McNamara III, Y.T. Didenko and K.S. Suslick, Nature 401, 772 (1999). 
53 N. de la Rosa-Fox, M. Piñero, R. Litran and L. Esquivias, J. Sol-Gel Sci. Tech., 26, 947 (2003)

54 G. J. Price, Ultrasonics Sonochem. 3, 5229 (1996).

55 J. L. Luche, in "Current Trends in Sonochemistry" (G. J. Price, Ed.), p. 34. RSC, Cambridge, 1992.

56 AS. Gyorgi, Nature 131, 278 (1933)

57 G.J. Price, E.N. Wallace and A.M. Patel, in "Silicon Containing Polymers" Ed. R.G. Jones, R. Soc. Chem., Cambridge, UK (1995) p. 147.

58 S.I. Nikitenko, Y. Koltypin, D.M. Pickup, E.R.H. Van-Eck and A. Gedanken, Ultrasonics Sonochem. (2002).

59 E. Blanco, L. Esquivias, R. Litran, M. Piñero, M. Ramírez-del-Solar, and N. de la Rosa-Fox, Appl. Organomet. Chem. 13, 399 (1999).

60 J. Zarzycki, Heterogeneous Chem. Rev. 1, 243 (1994).

61 J. P. Lorimer and T. J. Mason, Chem. Soc. Rev. 16, 239 (1987).

62 E. A. Neppiras, Ultrasonics 22-1, 25 (1984).

63 T. J. Mason, “Practical Sonochemistry.” Ellis Horwood, Chichester, 1991.

64 P. Kruus, Ultrasonics 21, 201 (1983).

65 K. Morita, Y. Hu, and J. D. Mackenzie, J. Sol-Gel Sci. Technol. 3, 109 (1994).

66 P. Boudjouk, in "Science of Ceramics Chemical Processing", L. L. Hench and D. R. Ulrich, Eds., Wiley, New York (1986). p. 363.

67 G. J. Price, M. P. Hearn, E. Wallace, and A. M. Patel, Polymer 37, 2303 (1996).

68 M. Tarasevich, Ceram. Bull. 63, 500 (1984)(Abstract only).

69 L. Esquivias and J. Zarzycki, in "Current Topics on Non Crystalline Solids" (M. D. Baró and N. Clavaguera, Eds.), p. 409. World Scientific, Singapore, 1986.

70 L. Esquivias and J. Zarzycki, in "Ultrastructure Processing of Ceramics, Glasses and Composites" (J. D. Mackenzie and D. R. Ulrich, Eds.), p. 255. Wiley, New York, 1988.

71 N. de la Rosa-Fox, L. Esquivias, and J. Zarzycki, Diffusion Defect Data 53/54, 363 (1987).

72 E. Blanco, Ph.D. Thesis. University of Cádiz, Spain, 1993.

73 D. Hummel, I. Torriani, A. Ramos, A. F. Craievich, N. de la Rosa-Fox, and L. Esquivias, Mater. Res. Soc. Symp. Proc. 246, 673 (1994). 
74 R. Litrán, P. M. Petersen, P. M. Johansen, L. Linvold, M. Ramírez-del-Solar, and E. Blanco, J. Appl. Phys. 81, 7728 (1997).

75 P. M. Petersen, R. Litrán, P. M. Johansen, and L. Lindvold, SPIE Proc. 2788, 202 (1996).

76 R. Erce-Montilla, M. Piñero, N. de la Rosa-Fox, A. Santos, and L. Esquivias, J. Mater. Res. 16, $2572(2001)$.

77 M. García-Hernández, R. Jiménez-Riobóo, C. Prieto, J. J. Fuentes-Gallego, E. Blanco, and M. Ramírez-del-Solar, Appl. Phys. Lett. 69, 3827 (1996).

78 R. Jiménez-Riobóo, M. García-Hernández, C. Prieto, J. J. Fuentes-Gallego, E. Blanco, and M. Ramírez-del-Solar, J. Appl. Phys. 81, 7739 (1997).

79 K. Morita, Y. Hu, and J. D. Mackenzie, Mater. Res. Soc. Symp. Proc. 271, 693 (1992).

80 D.A. Donatti and D.R. Vollet, J. Sol-Gel Sci. Technol. 4, 99 (1995).

81 D.A. Donatti and D.R. Vollet, J. Non-Cryst. Solids. 208, 99 (1996).

82 D.A. Donatti, A. Ibañez Ruiz and D.R. Vollet, Ultrasonics Sonochem. 9, 133 (2002).

83 D.R. Vollet, D.A. Donatti and A. Ibañez Ruiz, J. Sol-Gel Sci. Technol. 15, 5 (1999).

84 D.A. Donatti, D.R. Vollet and A. Ibañez Ruiz, J. Sol-Gel Sci. Technol. 18, 5 (2000).

85 H.-J. Tiller, R. Gobel, and U. Hartung, J. Non-Cryst. Solids 105, 162 (1988).

86 H. Coudurier, R. Baudru, and J. B. Donnet, Bull. Soc. Chim. Fr. 9, 3147, 3154, 3161 (1971).

87 Y. Hoshino and J. D. Mackenzie, J. Sol-Gel Sci. Technol. 5, 83 (1995).

88 L.L. Hench and J.K. West, Chem. Rev. 90, 33 (1990)

89 G. Orcel and L.L. Hench, J. Non-Cryst. Solids 79, 177 (1986).

90 T. Adachi and S. Sakka, J. Mater. Sci. 22, 4407 (1987)

91 L.L. Hench, in Science of Ceramic Chemical Processing, Eds. L.L. Hench and D.R. Ulrich, Wiley, NY, (1986) p. 52

92 T. Woigner, PhD Thesis, University of Montpellier, France (1984).

93 P.H. Tewari, A.J. Hunt and K.D. Loffus, Mater. Lett., 3, 363 (1985)

94 S. Bruin and K.Ch.A.M. Luyben in Advances in Drying, vol. 1, ed. A.S. Mujumdar, Hemisphere, NY, (1980) p. 155.

95 B.E Warren in X-Ray Difraction, Adison-Wesley, Reading MA (1969) Ch. 10

96 A. D’Anjou and F. Sanz, J. Non-Cryst. Solids, 28, 319 (1978) 
97 W. Wei, J. Non-Cryst. Solids 81, 239 (1986).

98 M.C. Barrera-Solano, N. De la Rosa-Fox and L. Esquivias, J. Non-Cryst. Solids, 147\&148, 194 (1992)

99 A. B. Rosenthal and S. Garofalini, J. Non-Cryst Solids 107, 65 (1988).

100 B. E. Warren, “X-ray Diffraction.” Addison-Wesley, New York, 1969.

101 Glatter O and Kratky O, Small Angle X-Ray Scattering, Academic Press, London, (1982).

102 H. Brumberger, Modern Aspects of Small-Angle Scattering, NATO ASI vol. 451, Kluwer A.P., Dordrecht, (1995)

103 S. Brunauer, P.H. Emmett and E. Teller, J. Am. Chem. Soc., 60, 309 (1938)

104 E.P. Barret, L.G. Joyner and P.P. Halenda, J. Am. Chem. Soc., 73, 373 (1951)

105 D.W. Schaefer, Mater. Res. Soc. Bull. 8, 22 (1988)

106 J. Texeira in On Growth and Form, Eds. H.E. Stanley and N. Ostrowski, Martinus Nijhoff, Dordrecht, (1986) p. 145

107 P. Meakin, Ann. Rev. Phys. Chem., 39, 237 (1988)

108 T.A. Witten and L.M. Sander, Phys. Rev. Lett., 47, 1400 (1981)

109 C.J. Brinker, K.D. Keefer, D.W. Schaefer, R.A. Assink, B.D. Kay and C.S. Ashley, J. NonCryst. Solids, 63, 45 (1984)

110 M. Fleischmann, D.J. Tildesley and R.C. Ball, Eds. in Fractals in the Natural Sciences, Princeton University Press, New Jersey, (1989)

111 W. Ruland, J. Appl. Cryst., 4, 70 (1971)

112 J.T. Koberstein, B. Morra and R.S. Stein, J. Appl. Cryst., 13, 34 (1980)

113 A.J. Hurd, D.W. Shaefer and A.M. Glines, J. Appl. Cryst., 21, 864 (1988)

114 K.D. Keefer and D.W. Schaefer, Phys. Rev. Lett., 56, 2376 (1986)

115 M. Ramirez-del-Solar, L. Esquivias, A.F. Craievich and J. Zarzycki, J. Non-Cryst. Solids, $147 \& 148,206$ (1992)

116 I. Langmuir, J. Am. Chem. Soc., 40, 1361 (1919)

117 S.J. Gregg and K.S.W. Sing in Adsorption, Surface Area and Porosity, Academic Press, London, (1982)

118 F. Rouquerol, J. Rouquerol and K.S.W. Sing in Adsorption by Powders and Porous Solids, Academic Press, San Diego, (1999) 
119 M. Kruk and M. Jaroniec, Chem. Mater., 13, 3169 (2001)

120 J. Thompson (Lord Kelvin), Phil. Mag., 47, 448 (1871)

121 R.W. Cranston and F.A. Inkley, Adv. Catal., 9, 143 (1957)

122 D. Dollimore and G.R. Heal, J. Appl. Chem., 14, 109 (1964)

123 G. Horvath and K. Kawazoe, J. Chem. Eng. Jpn., 16, 470 (1983)

124 J. Rodriguez-Ortega and L. Esquivias, J. Sol-Gel Sci. Tech., 8, 117 (1997)

125 L. Esquivias, J. Rodríguez-Ortega, C. Barrera-Solano and N. de la Rosa-Fox, J. Non-Cryst. Solids, 225,239 (1999)

126 J. Rodriguez-Ortega, PhD thesis, Universidad de Cadiz, Spain (1996)

127 J.D. Bernal and J. Mason, Nature, 188, 910 (1960)

128 G.D. Scott, Nature, 188,908 (1960)

129 J.L. Finney, Proc. R. Soc (London) A319, 479 (1970)

130 J. Zarzycki, J. Non-Cryst. Solids, 147\&148, 176 (1992)

131 J.L. Finney and J. Wallace, J. Non-Cryst. Solids, 43, 165 (1981)

132 J. Zarzycki, J. Non-Cryst. Solids 121 (1990) 110-118.

133 V. Morales-Florez, N. de la Rosa-Fox, M. Piñero and L. Esquivias, J of Sol-Gel Sci. and Tech. 35, (2005) 203-210.

134 K. Yamahara, K. Okazaki. Fluid Phase Equilibria 144 (1998) 449-459.

135 S. H. Garofalini, G .E. Martin. J. Phys. Chem. 98 (1994) 1311-1316.

136 B. P. Feuston, S. H. Garofalini. J. Phys. Chem. 94 (1990) 5351-5356.

137 A. Emmerling, J. Fricke. J. Sol-Gel Sci. and Tech. 8 (1997) 781-788.

138 M. Grzegorczyk, M. Rybaczuk, K. Maruszewski. Chaos, Solitons \& Fractals 19 (2004) 10031011.

139 H. Ma, J. H. Prevost, G. W. Scherer. International Journal of Solids and Structures 39 (2002) 4605-4614.

140 H. Ma, A. P. Roberts, J. H. Prevost, R. Jullien, G. W. Scherer. J. Non-Cryst. Solids 277 (2000) 127-141.

141 H. Ma, J. H. Prevost, R. Jullien, G. W. Scherer, J. Non-Cryst. Solids 285 (2001) 216-221. 
142 T. Woignier, J. Reynes, A. H. Alaoui, I. Beurroies, J. Phallipou, J. Non-Cryst. Solids 241 (1998) 45-52.

143 J. Primera, A. Hasmy, T. Woignier, J. Sol-Gel Sci. and Tech. 26 (2003) 671-675.

144 T. Woignier, F. Despetis, A. Alaoui, P. Etienne, J. Phalippou, J.Sol-Gel Sci. and Tech. 19 (2000) 163-169.

145 T. Woignier, J. Phalippou, J. Non-Cryst. Solids 100 (1988) 404-408.

146 A. Rumpf, Chem. Ing. Tech. 30 (1958) 144.

147 Persistence Of Vision, www.povray.org. Last visit, 23/nov/2006.

148 V. Morales-Flórez, M. Piñero, N. de la Rosa-Fox, L. Esquivias, J.A. Anta, J. Primera, J. NonCryst. Solids, 354, 193-198 (2008)

149 M.C. Barrera-Solano, N. de la Rosa-Fox and L. Esquivias. J. Non-Cryst. Solids 147/148 (1992) 194-200.

150 Piñero M., Atik M., Zarzycky J., J. Non-Cryst. Sol.. 147\&148, 523 (1992)

151 Piñero M., Zarzycki J., J. Sol-Gel Sci.Tech., 1, 275 (1994)

152 M. Piñero, R. Litran, C. Fernández-Lorenzo, E. Blanco, M. Ramírez-del-Solar, N. De la Rosa-

Fox, L. Esquivias, A. Craievich, J. Zarzycki, J. Sol-Gel Sci.Tech., 2, 689 (1994)

153 A. Craievich, N. De la Rosa-Fox, E. Blanco, M. Piñero, M. Ramírez del Solar, L. Esquivias, Nanostruc. Mater., 5 (3) 363 (1995)

154 L. Esquivias, V. Morales-Flórez, M. Piñero, N. de la Rosa-fox, J. Ramírez, J. González-Calbet, A. Salinas, M. Vallet-Regí, Mater. Res. Soc. Symp. Proc. Vol.847 EE12.1.1 (2005)

155 J. A. Toledo-Fernández, R. Mendoza-Serna, V.Morales-Flórez, N. de la Rosa-Fox, A. Santos, M. Piñero, L. Esquivias, Bol. Soc. Exp. Ceram. V., 46 [3] 138-144 (2007)

156 A. Santos, J. A. Toledo-Fernández, R. Mendoza-Serna, L. Gago-Duport, N. de la Rosa-Fox, M.Piñero, L. Esquivias, Ind. Eng. Chem. Res, 46, 103-107 (2007)

157 A. Santos, M. Ajbary, A. Kherbeche, M. Piñero, N. de la Rosa-Fox, L. Esquivias, J. Sol-Gel Sci. Tech. DOI: 10.1007/s10971-007-1672-1 (2008)

158 Jain, R.K., Lind, R.C., J. Opt.Soc. Am. 73, 647 (1983)

159 J. Butty,Y.Z. Hu, N. Peyghambarian, Y.H. Kao and J.D. Mackenzie, Appl. Phys. Lett. 67, 2672 (1996).

160 J. Butty, N. Peyghambarian, Y.H. Kao and J.D. Mackenzie, Appl. Phys. Lett. 69, 3224 (1996).

161 K.L. Shaklee, R.E. Nahory and R.F.Leheny, J. of Lumin. 7, 284 (1973). 
162. N. Peyghambarian, S. Koch and A. Mysyrowicz, in "Introduction to Semiconductor Optics". (Prentice-Hall, New Jersey, 1993). Pp. 245-253.

163. A. Lipovskii, E. Kolobkova, V. Petrikov, I.Kang, A. Olkhovets, T. Krauss, M. Thomas, J. Silcox, F. Wise, Q. Shen, S. Kycia, Appl. Phys. Lett. 71(23), 3406,(1997)

164. N. F. Borrelli, D. W. Smith, J. Non-Cryst. Solids., 180, 25 (1994).

165. M. Mukherjee, A. Datta, D. Chakravorty, J. Mater. Res., 12(10), 2507, (1997)

166. F del Monte, Y. Xu, J. D. Mckenzie, J. Sol-Gel Sci.\&Tech., 17, 37 (2000)

167. S. Gallardo, M. Gutiérrez, A. Henglein, E. Janata, Ver. Bunsenges. Phys. Chem. 93,1080, (1989)

168. M. Guglielmi, A. Martucci, J. Fick, G. Vitrant, J. Sol-Gel Sci.\&Tech., 11, 229 (1998)

169. A. Martucci, P. Innocenzi, J. Fick, J.D. Mackenzie, J. Non-Cryst. Solids., 244, 55, (1999)

170. L. Spanhel, E. Arpac, and H. Schmidt, J. Non-Cryst. Solids., 147\&148, 657, (1992)

171. N.N. Parvathy, G.M. Pajonk, and A. Venkateswara, J. Cryst. Growth, 179, 249, (1997).

172. N.N. Parvathy, G.M. Pajonk, and A. Venkateswara, Mat. Res. Bull., 32(4), 397, (1997)

173. A. Martucci, M. Guglielmi, and K. Urabe, J. Sol-Gel Sci. \&Tech., 11, 105 (1998).

174. A. Martucci, J. Fick, J. Scell, G. Battaglin and M. Guglielmi, J. Appl. Phys. 86(1), 79 (1999).

175. M. Guglielmi, A. Martucci, E. Menegazzo, G.C. Righini, S. Pelli, J. Fick, G. Vitrant, J. SolGel Sci. \& Tech., 8, 1017, (1997)

176. H. Lin, E. Bescher, J.D. Mackenzie, H.Dai, and O.M. Stafsudd, J. Mat. Sci., 27, 5523, (1992).

177. P. T. Guerreiro, S. Ten, N. F. Borrelli, J. Butty, G. E. Jabbour, N. Peyghambariam, Appl. Phys. Lett. 71(12), 1595, (1997)

178 - A. Martucci, J. Fick, J. Scell, G. Battaglin and M. Guglielmi, J. Appl. Phys. 86(1), 79 (1999).

179 M. Piñero, N. de la Rosa-Fox, R. Erce-Montilla and L. Esquivias, J. Sol-Gel Sci. Tech., 26, 527 (2003)

180 N. de la Rosa-Fox, R. Erce-Montilla, M. Piñero and L. Esquivias, Opt. Mater., 22, 1 (2003)

181 - G.Banfi, V. Degiorgio and B. Sepeit, J. Appl. Phys. 74, 6925 (1993).

182 - P. Debye and M. Bueche, J. Appl. Phys. 20, 518 (1949).

183 - P. Debye, H.R. Anderson Jr. and H. Brumberger, J. Appl. Phys. 28, 179 (1957). 
184 - N. Ashcroft, J. Lekner, Phys. Rev, 145, 83 (1966)

185 E. Geissler, F. Horkay, A.M. Hecht and C. Rochas, Polymer 38 (1), 15 (1997).

186 K. Morita, Y. Hu and J.D. Mackenzie, Mat. Res. Soc. Symp. Proc., Vol 271, 693 (1992)

187 E. Blanco, L. Esquivias, R. Litran, M. Piñero, M. Ramírez-del-Solar and N. de la Rosa-Fox, Appl. Organomet. Chem. 13, 399 (1999)

188 N. de la Rosa-Fox, L. Esquivias and M. Piñero in Handbook Of Organic-Inorganic Hybrid Materials and Nanocomposites, Vol. 1, Ed. H.S. Nalwa, American Scientific Publishers, USA (2003) Ch. X (in press)

189 J.D. Mackenzie, J. Ceram. Soc. Japan 101, 1 (1993)

190 B. Dunn, J.D. Mackenzie, J.I. Zink and O.M. Stafsudd, SPIE Proc. 1328, 174 (1990)

191 H. Zang and C. Pantano, J. Am. Ceram. Soc. 73, 958 (1990).

192 F. Babonneau, L. Bois and J. Livage, J. Non-Cryst. Solids 147\&148, 280 (1992).

193 J.D. Ferry, “Viscoelastic properties of Polymers”, 3rd Ed. (Wiley, NY, 1980).

194 I.M. Ward, J. Sweeney. "An introduction to the mechanical properties of solid polymers". (2nd Ed.) John Wiley \& Sons, (2004).

195 Schuh, C.A., Mater. Today, 2006, 9, 32-40.

196 Marshall, G.W., Habelitz, S., Gallagher, R., Balooch, M., Balooch, G. and Marshall, S.J., J. Dent. Res. 2000, 80, 1768.

197 Ebenstein, D.M. and Pruitt, L.A., J. Biomed. Mater. Res. A, 2004, 69A, 222.

198 Carrillo, F., Gupta, S., Balooch, M., Marshall, S. J., Marshall, G.W., Pruitt, L. and Puttlitz, C.M., J. Mater. Res., 2005, 20, 2820-2830.

199 Moner-Girona, M., Roig, A., Molins, E., Martínez, E. and Esteve, J. Appl. Phys. Lett., 1999, 75, 653-655.

200 Oliver, W. C. and Pharr, G.M., J. Mater. Res., 1992, 7, 1564-1583.

201 Pharr, G.M., Oliver, W.C. and Brotzen, F.R., J. Mater. Res., 1992, 7, 613-617.

202 Piñero, M., Morales-Flórez, V., de la Rosa-Fox, N. and Esquivias, L., Mechanical properties of hybrid aerogels, Bol. Soc. Esp. Ceram. V., 2005, 44(5), 291-293.

203 Ferry, J.D., “Viscoelastic Properties of Polymers”, Wiley, N. Y., 3rd. ed., 1980.

204 Callister Jr., W. D. “Introducción a la Ciencia e Ingeniería de los Materiales”, Ed. Reverté, Barcelona, 1995. 
205 U. Keiderling, Physica B, 234-236, (1997), 1111.

206 Kirste, R.G. and Oberthur, R.C., in "Small Angle X-ray Scattering”, Ed. Glatter, O. and Kratky, O., Academic Press, (1982), Chap. 12, 387-431.

207 Pedersen, J.S., J. Appl. Cryst., 33, (2000), 637-640.

208 M. Kamitahara, M. Kawashita, N. Miyata, T. Kokubo and T. Nakamura, J. Mat. Sci.: Mat. In Med. 13 (2002) 1015-1020

209. Hench L. L. J. Am. Ceram. Soc. 81 (1998) 1705.

210 Wu JC-S, Sheen J-D, Chen S-Y, Fan Y-Ch. Ind Eng Chem Res 40, 3902 (2001)

211 Tai CY, Chen W-R, Shih S-M AIChE J 52, 292 (2006)

212 Zevenhoven R, Eloneva S, Teir S Catal Today 115, 73 (2006) 